\title{
Prolonged Repetitive Head Trauma Induces a Singular Chronic Traumatic Encephalopathy-Like Pathology in White Matter Despite Transient Behavioral Abnormalities
}

\author{
Denise I. Briggs, ${ }^{* \dagger}$ Mariana Angoa-Pérez, ${ }^{* \dagger}$ and Donald M. Kuhn ${ }^{* \dagger}$ \\ From the Research and Development Service, * John D. Dingell VA Medical Center, Detroit; and the Department of Psychiatry and Behavioral \\ Neurosciences, ${ }^{\dagger}$ Wayne State University School of Medicine, Detroit, Michigan
}

\author{
Accepted for publication \\ July 11, 2016. \\ Address correspondence to \\ Denise I. Briggs, Ph.D., \\ John D. Dingell VA Medical \\ Center, Research and Devel- \\ opment Service, 4646 \\ John R St., Detroit, MI 48201- \\ 1916. E-mail: dbriggs@med. \\ wayne.edu or dibriggs@ \\ stanford.edu.
}

\begin{abstract}
Repetitive mild traumatic brain injury (rmTBI), resulting from insults caused by an external mechanical force that disrupts normal brain function, has been linked to the development of neurodegenerative diseases, such as chronic traumatic encephalopathy and Alzheimer disease; however, neither the severity nor frequency of head injury required to trigger adverse behavioral outcomes is well understood. In this study, the administration of 30 head impacts using two different weights to lightly anesthetized, completely unrestrained mice established a paradigm that simulates the highly repetitive nature of sports- and military-related head injury. As the number of head impacts increases, the time to recover consciousness diminishes; however, both the sensorimotor function and behavioral outcomes of impacted mice evolve during the ensuing weeks. Postmortem analyses reveal robust Alzheimer disease and chronic traumatic encephalopathy-like conditions that manifest in a singular manner throughout the white matter concomitant with evidence of chronic oligodendrogenesis. Our data suggest that latency to recover the righting reflex may be an inadequate measure of injury severity and imply that exposure to repeated head impacts may mask the severity of an underlying and developing neuropathologic condition that does not manifest itself until long after head collisions cease. In addition, our data indicate that there is a cumulative and dose-dependent effect of repetitive head impacts that induces the neurobehavioral and neuropathologic outcomes seen in humans with a history of rmTBI. (Am J Pathol 2016, 186: 2869-2886; http://dx.doi.org/10.1016/j.ajpath.2016.07.013)
\end{abstract}

Traumatic brain injury (TBI) is the result of an insult from an external mechanical force that disrupts normal brain function. In the United States, approximately 1.6 million to 3.8 million TBIs occur annually and many are sports related. ${ }^{1,2}$ Most of these injuries are mild and repetitive and cannot be detected by neuroimaging.

Repetitive mild TBI (rmTBI) is associated with the development of several comorbid psychiatric illnesses, particularly depression, ${ }^{3-7}$ and can result in cognitive impairments that involve executive function and memory. ${ }^{8-12}$ There is increasing concern that a major outcome of repetitive head impacts could be chronic traumatic encephalopathy (CTE). CTE is a slowly developing neurodegenerative condition that is characterized by progressive brain atrophy, accumulation of hyperphosphorylated tau (p-tau) and aggregates of transactive response DNA-binding protein 43 (TDP-43), myelinated axonopathy, neuroinflammation, degeneration of white matter tracts, and loss of central white matter. $^{7,13-16}$ CTE is also accompanied by cognitive disruption and emergence of psychiatric-like behavioral abnormalities. ${ }^{14}$ CTE is not usually detectable during the time when individuals are actively exposed to repeated head impacts (eg, in younger athletes and military personnel), and

Supported by Department of Veterans Affairs grant 5IO1RX000375 (D.M.K.); and a New Investigator grant from the Department of Psychiatry and Behavioral Neurosciences, Wayne State University School of Medicine (D.I.B.).

Disclosures: None declared. 
a definitive diagnosis usually must await postmortem examination of the brain.

Few animal models of rmTBI use methods that are capable of administering truly repetitive $(>2)$ head impacts, ${ }^{17-25}$ and those that administer $\geq 30$ impacts are limited in their ability to simulate the head impact kinematics observed in athletes. ${ }^{26-28}$ Although these methods are advantageous in that they administer large numbers of head impacts, they require that animals be restrained before receiving head impact ${ }^{26,27}$ or use a gel-filled base to decelerate the head after impact. ${ }^{28}$

To our knowledge, ours is the first study to administer 30 head impacts using two different weights during an extended period to lightly anesthetized, completely unrestrained mice. This study highlights how the sensorimotor, psychiatric, and neuropathologic outcomes of rmTBI evolve over time as a function of impact force. We report that repetitive head impacts in mice result in the gradual reduction to control levels of the time required to recover the righting reflex, a corollary of a reduction in the loss of consciousness (LOC) in humans. Initial impacts caused significant increases in the time required to regain consciousness, but after 14 impacts head-struck mice were no longer different from controls. This adaptation was not neuroprotective because impacted mice developed signs of CTE and behavioral alternations as documented in athletes. ${ }^{14,29}$ Together, these studies indicate that the outcomes of rmTBI are by and large dose dependent, that the behavioral manifestations of rmTBI are not temporally salient, and that white matter tracts, particularly those distant from the point of impact, are prone to develop significant neuropathologic conditions.

\section{Materials and Methods}

\section{Animals and rmTBI Model}

All procedures that involved the use of animals in this study were reviewed and approved by the Wayne State University Institutional Animal Care and Use Committee. Forty male C57Bl $\backslash 6$ mice (7 to 8 weeks old) weighing approximately $25 \mathrm{~g}$ were used (Harlan, Indianapolis, IN). To avoid the potential confounding neuroprotective effects of female sex hormones $^{30-32}$ and because all documented cases of CTE have been reported in male athletes or military personnel, ${ }^{14,16,29,33,34}$ male mice were selected for use in the present studies. Mice were housed five per cage on a 12-hour light/dark cycle in a temperature-controlled room with ad libitum access to food and water. Since publication of our original method of rmTBI, ${ }^{25}$ improvements have been made to the apparatus (Figure 1). A platform consisting of two magnetically adjoined transparent acetate sheets supports the animal before head impact. The platform is secured to the H-shaped Plexiglas frame $(15-\mathrm{cm}$ length $\times 9$-cm width $\times 23-\mathrm{cm}$ depth) by brass hinges. The saloon door-style platform has a weight limit of $35 \mathrm{~g}$,
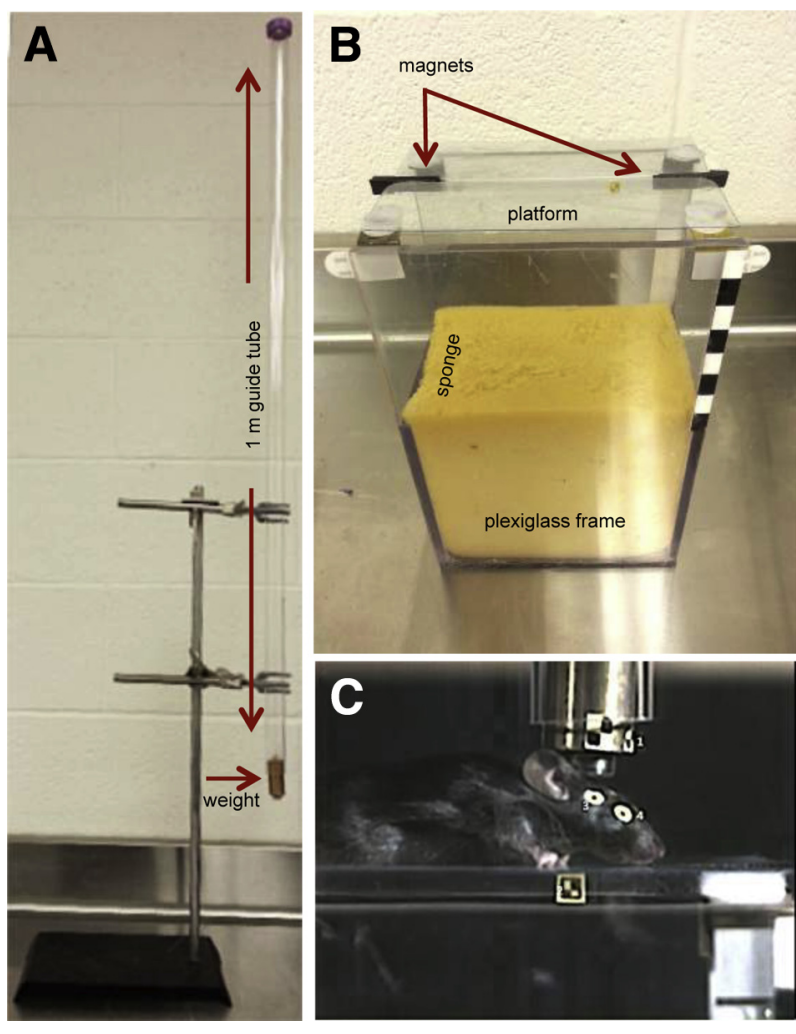

Figure 1 Repetitive mild traumatic brain injury (rmTBI) apparatus. The essential components and arrangement of the rmTBI apparatus are shown: weight drop guide tube (A), updated platform (B), and mouse atop platform before receiving head impact (C).

which ensures that the platform provides minimal resistance to movement on head impact. Solid brass weights (19-mm diameter) weighing 75 or $95 \mathrm{~g}$ are dropped from a height of $1.0 \mathrm{~m}$ through a clear guide tube $(20-\mathrm{mm}$ diameter $\times 1.0$ $\mathrm{mm}$ length). A small steel cap $(2 \times 10 \mathrm{~mm})$ is glued to the bottom of each weight to restrict the zone of contact to the top of the mouse head between the ears. Mice are placed into an enclosed induction chamber (approximately $1 \mathrm{~L}$ in size) that contains $0.5 \mathrm{~mL}$ of isoflurane in a cotton ball. This yields a steady $2 \%$ to $4 \%$ concentration for inhalation. Mice are lightly anesthetized with isoflurane (ie, until unresponsive to paw or tail pinch; approximately 1 to 2 minutes). The mouse is quickly positioned on the platform using markers so that its head is directly in the path of the falling weight. When the weight contacts the animal's head, the platform doors immediately release. A sponge cushion $(15-\mathrm{cm}$ length $\times 9$-cm width $\times 13-\mathrm{cm}$ depth) is located $10 \mathrm{~cm}$ below the stage to cushion the fall. The vertical traverse of the dropped weight is limited by Orvis Super Strong knotless tapered leader $(5 \mathrm{X})$, commercially available nylon flyfishing line (2.2-kg test, $0.53-\mathrm{mm}$ diameter). The weight is allowed to transverse the plane of the platform before being stopped by the tether and avoids rehits of the mouse's head. In this arrangement, the impact-induced acceleration and fall always involve a $180^{\circ}$ horizontal rotation of the mouse body and free movement of the head on impact. Animals were 
randomly divided into 3 groups: i) isoflurane only (ie, controls, $n=8$ ); ii) 30 head impacts with a 75 -g weight ( $n=16$ ); and iii) 30 head impacts with a $95-\mathrm{g}$ weight $(n=16)$. Controls were anesthetized on the same schedule as experimental mice and placed onto the platform of the apparatus but were not subjected to head impact. The rmTBI groups received one head impact per day for 5 days followed by 2 days of rest. This schedule was repeated for 6 weeks until 30 head impacts were administered in total. The mortality rates for the rmTBI $(75 \mathrm{~g})$ and $(95 \mathrm{~g})$ groups were $18.75 \%$ and $25 \%$, respectively. On the first day of head impacts, 4 animals in the 95-g group and 2 in the 75-g group died. One animal in the 75-g group died after the 13th head impact. Postmortem analysis revealed no evidence of bleeding or skull fracture in any animals that died or those used for neuropathologic analysis.

\section{Sensorimotor and Neurologic Assessment}

\section{Recovery of Righting Reflex}

To assess the neurologic outcomes of rmTBI, latency to recover the righting reflex was recorded each day for 30 days after isoflurane-induced anesthesia (controls) or anesthesia followed by head impact as previously reported. ${ }^{25}$ Immediately after head impact, mice were placed in a clean cage with fresh bedding in a supine position. The time it took each animal to adopt a prone position was recorded.

\section{Balance and Motor Coordination}

To determine whether head impacts caused immediate or delayed-onset sensorimotor impairment, performance was assessed using an accelerating Rotarod as previously described. ${ }^{25}$ Animals were tested on days 1 (immediate time point) and 28 (late time point) after the final head impact. Mice were placed onto the accelerating rod, which gradually increased in rotational speed from 4 to $>40 \mathrm{rpm}$ and left undisturbed until they fell off or reached the maximum time (300 seconds). Time spent on the apparatus was recorded for each animal.

\section{Locomotor Activity}

Locomotor activity was measured in four transparent plastic cages (AccuScan Instruments, Columbus, OH; $43 \times 42 \times 42 \mathrm{~cm}$ ) each covered by a removable perforated plastic lid. Controls (anesthetized, not impacted) and impacted mice were placed in the center of the cage and allowed to move freely for 30 minutes. During that time, activity was measured by 16 infrared light beam arrays in the horizontal and vertical axes. Motor activity was recorded on a computer and analyzed by AccuScan Fusion software version 3.5 (AccuScan, Columbus, OH). Total activity was defined as the sum of all beam breaks in both the horizontal and vertical planes during the entire session. Mice were tested twice on days 1 (immediate time point) and 35 (late time point) after the last head impact.

\section{Grip Strength Assessment}

A modified version of the weights test was used as described by Deacon ${ }^{35}$ to determine whether rmTBI affected grip strength. A paperclip is attached to a series of chains composed of steel links. Each link weighs approximately 13 $\mathrm{g}$, and each chain ranges from 1 to 7 links in length. Holding the mouse by the tail allows it to grasp the paper clip (and links attached) with its forepaws. Timing began as soon as the links were lifted off of the lab bench. Mice are required to hold each chain for 3 seconds before moving on to the next chain. The mouse is allowed three trials to satisfy the 3 -second criteria, with 10 -second intertrial intervals. The final score is equal to the product of the maximum number of links held for 3 seconds plus the time the animal was able to lift the next largest chain. Mice were tested on days 2 (immediate time point) and 28 (late time point) after the final head impact.

\section{Affective-Like Behavior and Cognitive Performance}

\section{Depression-Like Behavior}

Coat status was assessed as a measure of self-motivated care on days 2 (immediate time point) and 30 (late time point) after the final head impact as previously described. ${ }^{36-38}$ Seven body regions were evaluated: head, neck, forepaws, dorsal coat, ventral coat, hindlegs, and tail. Each received a score of 0 (healthy coat) or 1 (disheveled or damaged). The sum of the scores from all regions for each animal was used for statistical analyses.

\section{Cognitive Performance}

Cognitive function was assessed on one occasion (days 21 to 25 after the last head impact) using the Barnes maze spatial learning task as previously reported. ${ }^{39}$ Briefly, mice were trained to locate a darkened goal box under one of 40 open holes on the perimeter of a brightly lit maze platform using external room cues. The Barnes maze task requires 5 days to complete. Days 1 to 4 are training days and are used to assess acquisition. Each training day consisted of two trials with intertrial intervals of 30 minutes. The amount of time required for each mouse to locate and enter the goal box was recorded using EthoVision XT video tracking software version 9.0 (Noldus, Leesburg, VA). A memory test probe was performed on day 5 by removing the goal box.

\section{Assessment of Neuropathologic Conditions}

Detection of Reactive Gliosis, Alzheimer Disease-Like, and CTE-Like Alterations Using Immunohistochemistry

Fifty-three days after the final head impact, mice were sacrificed by decapitation. The brain was divided into two halves through the sagittal plane and postfixed. Immunohistochemical analyses were performed as previously described. ${ }^{40}$ Coronal sections $(25 \mu \mathrm{m})$ within the coordinates of 2.46-mm interaural and $-1.34-\mathrm{mm}$ bregma and $0.64-\mathrm{mm}$ interaural and $-3.16-\mathrm{mm}$ bregma were selected for analysis. ${ }^{41}$ The following primary antibodies were used: 

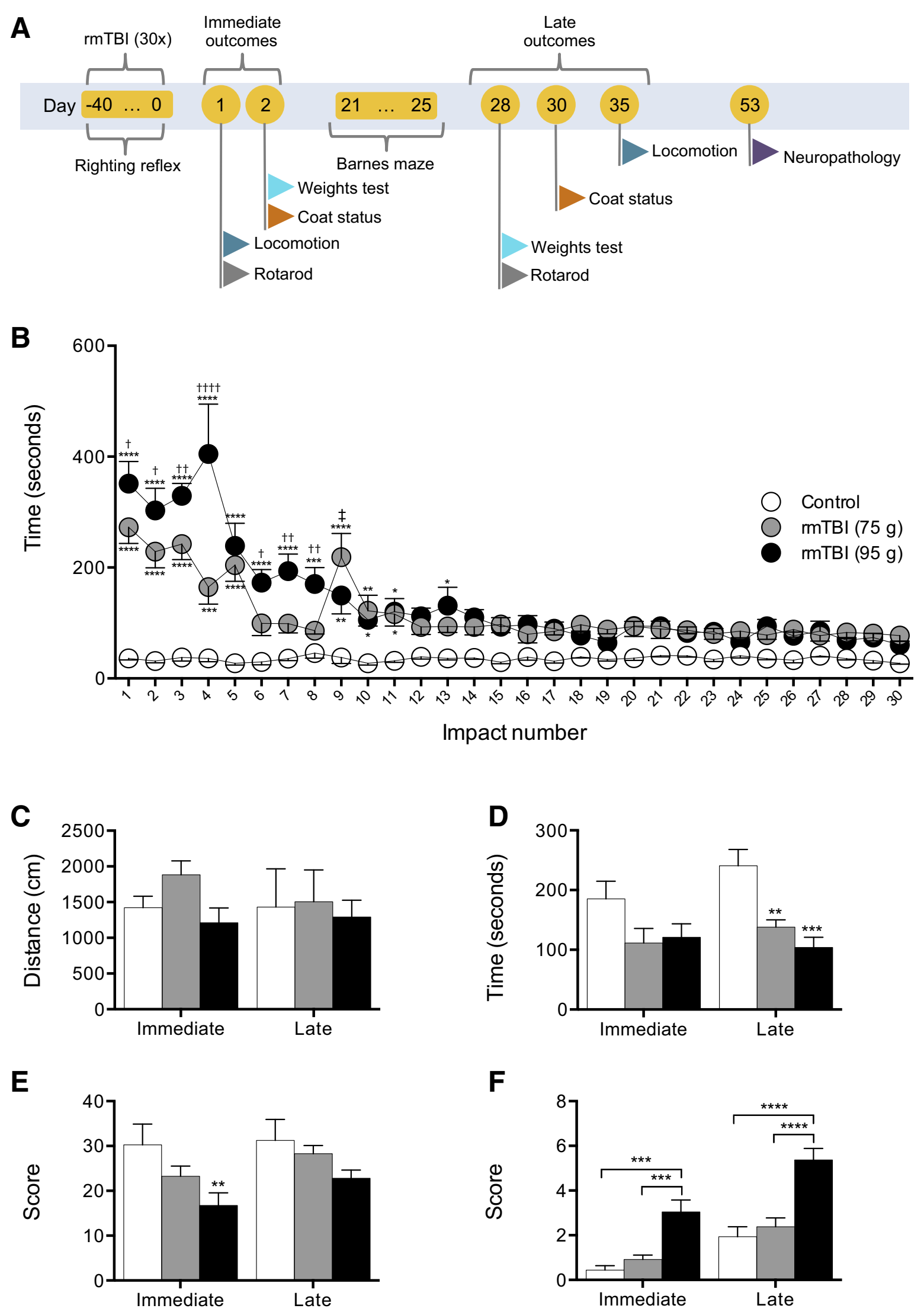

Control $\square$ rmTBI $(75 \mathrm{~g})$

rmTBI $(95 \mathrm{~g})$ 
anti- $\beta$-amyloid precursor protein ( $\beta$-App) (1:200; Invitrogen, Camarillo, CA); anti-A $\beta$ (1 to 42) (1:500; Abcam, Cambridge, MA); anti- $\beta$-amyloid (1:500; Dako, Richmond, VA); anti-glial fibrillary acidic protein (GFAP) (1:500; LabVision, Fremont, CA); anti-ionized calcium-binding adapter molecule 1 (Iba1) (1:500; Dako); anti-myelin basic protein (MBP) (1:500; Abcam); anti-p- $\tau$ AT8 (1:500; Thermo Scientific, Rockford, IL); anti-olig2 (1:500; Abcam); and anti-TARDBP (1:500; Abcam). Fixed sections were incubated with primary antibodies at $4^{\circ} \mathrm{C}$ overnight. Primary antibody amplification was achieved using the Vectastain Elite ABC kit (Vector Labs, Burlingame, CA). All commercially available antibodies were validated by the manufacturers. Sections were then washed with $1 \mathrm{~mL}$ of $1 \times$ phosphate-buffered saline (PBS)/0.1\% Triton X-100 three times for 5 minutes each. After the last wash, sections were incubated in $1 \times$ PBS for 5 minutes. The $1 \times$ PBS was removed, and $1 \mathrm{~mL}$ of diaminobenzidine staining solution (Vector Labs, Burlingame, CA) was added to each section and incubated for 5 to 10 minutes at room temperature until sufficient color developed. Diaminobenzidine staining solution was removed, and $1 \mathrm{~mL}$ of $1 \times$ PBS was added to each section to stop the diaminobenzidine reaction. Sections were mounted on Fisher SuperFrost Plus Slides and thoroughly dried. Sections were dehydrated through graded ethanol washes, incubated in Citrisolv for 5 minutes, and coverslipped with Permount. Slides were allowed to dry overnight before viewing. Images were acquired using an Olympus BX51 fluorescence microscope with a DP71 camera. Images acquired at $\times 4, \times 20, \times 60$, and $\times 100$ magnification from regions of interest were used for analysis. ImageJ software version 1.48v (NIH, Bethesda, MD; http://imagej.nih.gov/ij) was used to quantify immunoreactive cells.

\section{White Matter Alternations}

To assess demyelination after head impacts, coronal brain sections $(25 \mu \mathrm{m})$ were mounted as described above and incubated for 2 hours at $60^{\circ} \mathrm{C}$ in the Luxol fast blue solution (Abcam). Sections were then rinsed with distilled water, differentiated using lithium carbonate, and counterstained with cresyl violet. Images were acquired as described above, and the trace tool in ImageJ was used to measure the volume and area of white matter tracts. NeuroSilver staining was used to assess axonal injury (argyrophilic processes) using the FD NeuroSilver Kit II (FD Neurotechnologies, Inc., Columbia, MD). Coronal brain sections $(25 \mu \mathrm{m})$ were incubated and processed according to the manufacturer's protocol. Images were converted to 8-bit images and adjusted to a threshold of approximately 1.00 using ImageJ. The ratio of the area of positive signal to total area was determined. Values exceeding zero were indicative of positive silver staining.

\section{Experimental Timeline}

The timeline of all testing is presented in Figure 2A. To assess the temporal manifestation of the behavioral outcomes, mice were tested at two time points after the last head impact as follows: immediate time points for tests $<2$ days after the last head impact and late time points for tests $\geq 28$ days after the last head impact.

\section{Statistical Analysis}

Statistical analyses were performed using GraphPad Prism version 6.04 (GraphPad Software Inc., San Diego, CA). Behavioral and neuropathologic data and graphs are presented as means \pm SEM. Righting reflex, Rotarod, locomotion, weights test, coat status, and Barnes maze acquisition data were analyzed using two-way repeated-measures analysis of variance or mixed-measures analysis of variance (SPANOVA) followed by the Holm-Sidak or Sidak posthoc test as animals were tested repeatedly until they were sacrificed for neuropathology analysis. For analyses using analysis of variance, treatment refers to experimental group (isoflurane or isoflurane followed by head impact). Barnes maze probe test data were analyzed by one-way analysis of variance followed by the Holm-Sidak posthoc test. Then $\chi^{2}$ tests for independence were used to analyze the NeuroSilver data. All other immunohistochemistry data were analyzed by one-way analysis of variance followed by Tukey's honest significant difference (HSD) test. Differences were considered significant if $P<0.05$.

\section{Results}

\section{rmTBI Impairs Sensorimotor and Neurologic Performance and Elicits Depression-Like Behavior}

Mice were exposed to repeated head impacts using a 75- or 95-g weight dropped from $1 \mathrm{~m}$ to impart different forces of impact, and each level of impact caused a significant increase in the time required to regain consciousness (Figure 2B). The

\footnotetext{
Figure 2 Repetitive mild traumatic brain injury (rmTBI) delays recovery of the righting reflex and results in sensorimotor impairment, reduced strength, and depression-like behavior. A: Experiment timeline. B: Effects of rmTBI on latency to recover the righting reflex. Animals subjected to rmTBI took significantly longer to recover the righting reflex compared with controls. C: Quantification of locomotor activity at immediate and late time points. rmTBI does not result in locomotor impairment. D: Quantification of time spent on the Rotarod at immediate and late time points. rmTBI results in late-onset balance and motor coordination deficits. E: Quantification of scores on the weights test at immediate and late time points. rmTBI causes an acute, transient reduction in muscular strength. F: Quantification of coat status scores at immediate and late time points. rmTBI results in increased depression-like behavior. Symbols directly above error bars indicate differences compared with controls. Uppermost symbols indicate differences between rmTBI groups. Data are expressed as means \pm SD. $n=8\left(\mathbf{B}-\mathbf{F}\right.$, controls); $n=13(\mathbf{B}, \mathbf{D}-\mathbf{F}$, rmTBI $75 \mathrm{~g}) ; n=12(\mathbf{C}$, rmTBI $75 \mathrm{~g}$, and $\mathbf{B}-\mathbf{F}, \mathrm{rmTBI} 95 \mathrm{~g}) .{ }^{*} P<0.05,{ }^{* *} P<0.01,{ }^{* * *} P<0.001$, and $* * * * P<0.0001$ versus control; ${ }^{\dagger} P<0.05,{ }^{\dagger \dagger} P<0.01,{ }^{\dagger \dagger \dagger} P<0.0001$ versus rmTBI $(75 \mathrm{~g}){ }^{\ddagger} P<0.05$ versus rmTBI (95 g).
} 

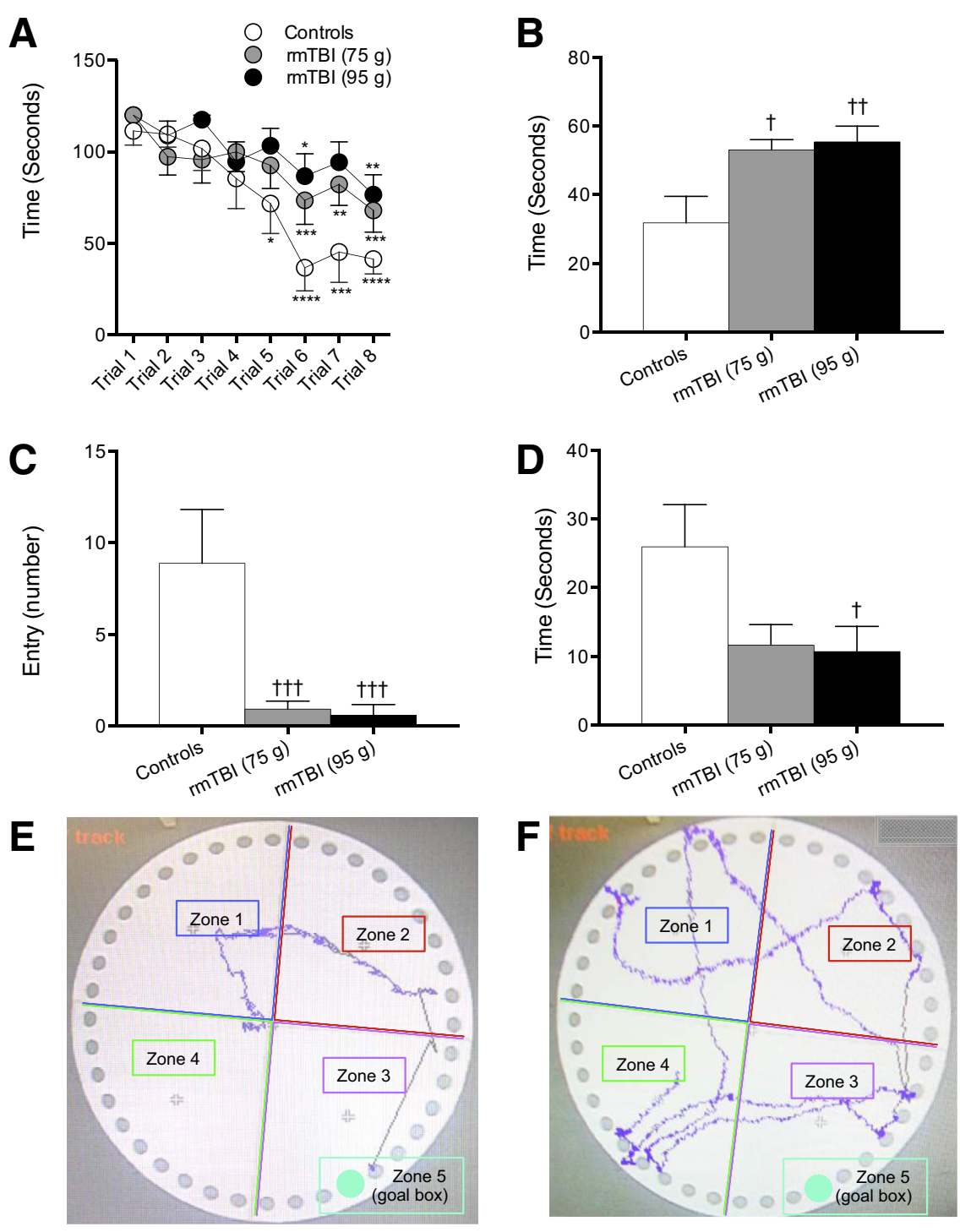

Figure 3 Repetitive mild traumatic brain injury (rmTBI) impairs acquisition learning and spatial memory recall. A: Quantification of latency to find and enter the goal box during the training phase of the Barnes maze. B: Quantification of latency to enter the goal box quadrant during the probe test. Animals subjected to rmTBI took significantly longer to enter the goal box quadrant. C: Quantification of the frequency at which animals entered the goal box zone during the probe test. Animals subjected to rmTBI entered the goal box zone less frequently. D: Quantification of the time spent in the goal zone quadrant during the probe test. Animals subjected to rmTBI spent less time in the goal zone quadrant. E: The Barnes maze zone delegations and a representative trace of a control mouse in route to the goal box zone during the probe test. F: Representative trace of a rmTBI $(95 \mathrm{~g})$ mouse searching for the goal box during the probe test. Data are expressed as means \pm SEM. $n=8$ (controls); $n=13$ (rmTBI $75 \mathrm{~g}) ; n=12$ (rmTBI $95 \mathrm{~g}) .{ }^{*} P<0.05$, ${ }^{* *} P<0.01,{ }^{* * *} P<0.001$, and ${ }^{* * * *} P<0.0001$ between differences within each group compared to trial $1 ;{ }^{\dagger} P<0.05,{ }^{\dagger \dagger} P<0.01$, and ${ }^{\dagger \dagger} P<0.001$ between rmTBI groups compared to controls. main effects of impact number $\left(F_{29,899}=15.62, P<0.0001\right)$ and treatment $\left(F_{2,31}=45.75, P<0.0001\right)$ and their interaction $\left(F_{58,899}=5.482, P<0.0001\right)$ were highly significant $(3 \times 30$ SPANOVA). Compared with controls, mice struck with the 75-g weight took longer to recover after impacts 1 to 5 and 9 to 11 , and mice struck with the $95-\mathrm{g}$ weight took significantly longer to recover the righting reflex after impacts 1 to 11 and 13 (Holm-Sidak, $P<0.05$ ). Compared with the rmTBI (75 g) group, the rmTBI $(95 \mathrm{~g})$ group had longer righting times after impacts 1 to 4 and 6 to 8 , whereas the rmTBI (75 g) group had longer righting times than the rmTBI (95 g) group after impact 9 only (Holm-Sidak, $P<0.05$ ). The increased latency to recover the righting reflex persisted in both groups until the 14th head impact, after which recovery times were not significantly different from controls. To ensure that impairments in sensorimotor function were not attributable to a reduction in gross motor activity, spontaneous locomotion was assessed at immediate and late time points after the last head impact. No significant differences between groups were found as shown in Figure 2C. To determine whether rmTBI caused a deficit in balance and coordination, mouse performance on the accelerating Rotarod was assessed at immediate and late time points after the last head impact. A significant reduction in balance and coordination was seen in both groups over time $(2 \times 3$ SPANOVA; $\left.F_{2,30}=12.00, P=0.0001\right)$. Although both groups exposed to rmTBI had reduced performance at the immediate time point after the last head impact, these differences were not different from control. Significant reductions in performance were seen, however, at the late time point after the last head impact for both rmTBI groups (Figure 2D) compared with controls [Holm-Sidak, rmTBI (75 g), $P<0.01$; rmTBI (95 g) $P<0.001]$. The effects of rmTBI on grip strength are shown in Figure $2 \mathrm{E}$. The main effect of treatment was significant $(2 \times 3$ SPANOVA; $\left.F_{2,30}=9.671, P=0.0006\right)$. The rmTBI (95 g) group had a significant reduction in grip strength when tested at the immediate time point after the last impact compared with 
controls (Holm-Sidak, $P<0.01$ ). This deficit resolved by the late time point after the last head impact and no betweengroup differences were seen. Together, these results indicate that despite the development of a compensatory change in recovery of consciousness in mice that indicates that mice were not subjected to a concussive blow to the head, significant changes in sensorimotor function can occur. These changes develop over different time frames (balance deficits slower than muscular grip strength reductions), and some resolve (muscular strength), whereas others do not (balance deficits). One comorbid outcome of repeated head impacts in humans is the emergence of affective disorders and particularly depression. ${ }^{3-6}$ Therefore, we tested mice for the expression of depression-like behavior, and the results are shown in Figure $2 \mathrm{~F}$. The main effects of time point $(2 \times 3$ SPANOVA; $\left.F_{1,30}=25.16, P<0.0001\right)$ and treatment $(2 \times$ 3 SPANOVA; $\left.F_{2,30}=30.62, P<0.0001\right)$ on coat status were significant and are indicative of increased depressionlike behavior (ie, self-neglect). The rmTBI (95 g) group had persistently higher scores than the control and rmTBI (75 g) groups (Holm-Sidak, $P<0.001)$ when tested at the immediate time point after the last of 30 head impacts. Although all groups had an expected aging-related reduction in coat status at the late time point after the last head impact by comparison to their respective immediate coat status score, the rmTBI (95 g) group continued to have depression-like behavior (Holm-Sidak, $P<0.0001$ ), and the rmTBI $(75 \mathrm{~g}$ ) group remained the same as from controls. These results suggest that the development of affective-like behaviors after rmTBI depends on impact force.

\section{rmTBI Reduces Cognitive Performance}

The effects of rmTBI on cognitive function are shown in Figure 3. Animals subjected to rmTBI had significant deficits in learning the Barnes maze task. The main effect of trial number on latency to enter the goal box during the training/acquisition phase of the Barnes maze was significant $\left(3 \times 8\right.$ SPANOVA; $\left.F_{7,210}=14.07, P<0.0001\right)$ as shown in Figure 3A. Subsequent trials were compared within groups to their respective trial 1 performance to assess acquisition learning over time. Although all groups performed significantly better on trial 8 compared with trial 1 , improvement was less pronounced in both rmTBI groups and especially the rmTBI $(95 \mathrm{~g})$ group [HolmSidak, controls, $P<0.0001$; rmTBI (75 g), $P<0.001$; rmTBI $(95 \mathrm{~g}), P<0.01]$. Controls had significant improvements by trial 4 and continued to improve through trial 8. During the probe test for memory, latency to enter the goal box zone, total number of entries into the goal box zone, and time spent in the goal box zone quadrant were measured. The main effect of treatment on latency to enter the goal box zone (one-way analysis of variance; $F_{2,30}=6.113, P=0.0059$ ) was significant (Figure 3B). Both rmTBI groups took longer to enter the goal box zone compared with controls (Holm-Sidak, $P<0.05$ and
$P<0.01$, respectively). The main effect of treatment on the number of goal box zone entries was also significant as seen in Figure 3C (one-way analysis of variance; $F_{2,30}=10.70, P=0.0003$ ). Both groups of mice subjected to rmTBI entered the goal box zone less frequently than controls (Holm-Sidak, $P<0.001$ for each). There was also a significant main effect of treatment on time spent in the goal box quadrant (one-way analysis of variance; $F_{2,30}=3.767, P=0.0347$ ). Figure 3D shows that, compared with controls, the rmTBI (95 g) group spent significantly less time in the goal box quadrant (HolmSidak, $P<0.05)$. The reduction in cognitive performance was therefore not dependent on impact force, and the lower weight used presently was sufficient to cause a significant cognitive deficit. The Barnes maze zone delegations and example traces of maze performance during the probe test for memory of a control and a rmTBI $(95 \mathrm{~g})$ mouse are shown in Figure 3, E and F, respectively.

\section{rmTBI Elicits a Persistent Reactive Gliosis}

There was no evidence of blood brain barrier disruption or loss of cortical matter below the point of impact to the skull in either rmTBI group 53 days after exposure of mice to the last of 30 head impacts (Figure 4). However, microscopic analyses revealed robust white matter disease, particularly throughout the optic tract (OT) and corpus callosum (CC). Iba1 was used to detect activated microglia in all groups in the OT and CC (Figure 5, A and B). Control, rmTBI (75 g), and $\mathrm{rmTBI}(95 \mathrm{~g})$ photomicrographs $(\times 2$ magnification $)$ are shown, and the OT and CC are shown at $\times 100$ magnification in Figure 5A. The main effect of treatment on Iba1 expression in the OT (one-way analysis of variance; $F_{2,14}=10.49, P=0.0016$ ) and CC (one-way analysis of variance; $F_{2,17}=4.727, P=0.0233$ ) was highly significant as seen in Figure 5B. Mice in both rmTBI groups had significantly more Iba1-labeled cells in the OT compared with controls (Tukey's HSD, $P<0.05$ and $P<0.01$, respectively), whereas only the rmTBI (95 g) group was different from controls in the CC with regard to Iba1 levels (Tukey's HSD, $P<0.05$ ). The effects of rmTBI on GFAP

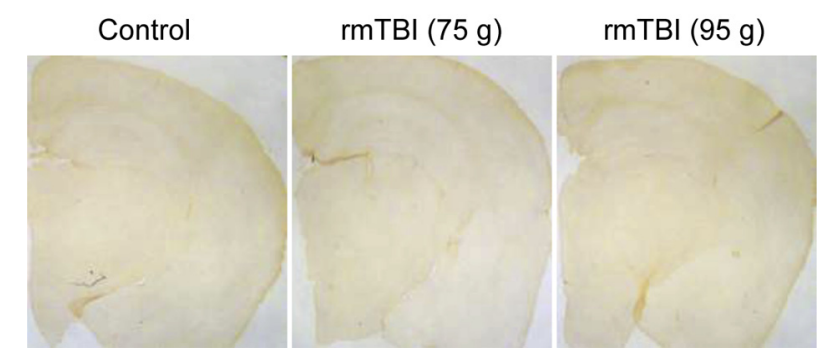

Figure 4 Repetitive mild traumatic brain injury (rmTBI) does not disrupt the blood brain barrier. The integrity of the blood brain barrier was assessed by immunohistochemical analysis of intracerebral levels of mouse IgG. Shown are representative photographs of control, rmTBI $(75 \mathrm{~g})$, and rmTBI $(95 \mathrm{~g})$ brain sections. Original magnification, $\times 2$. 
A

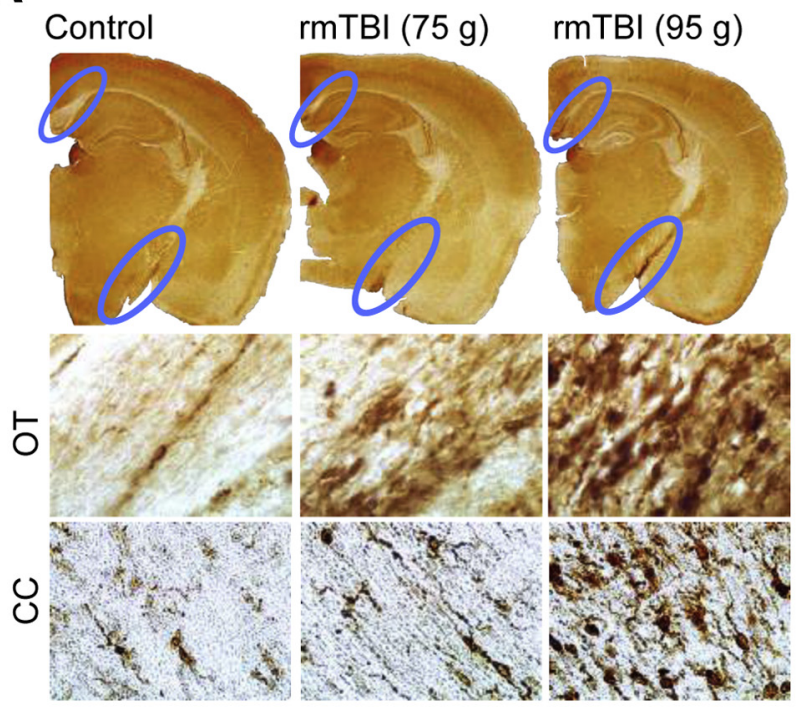

C

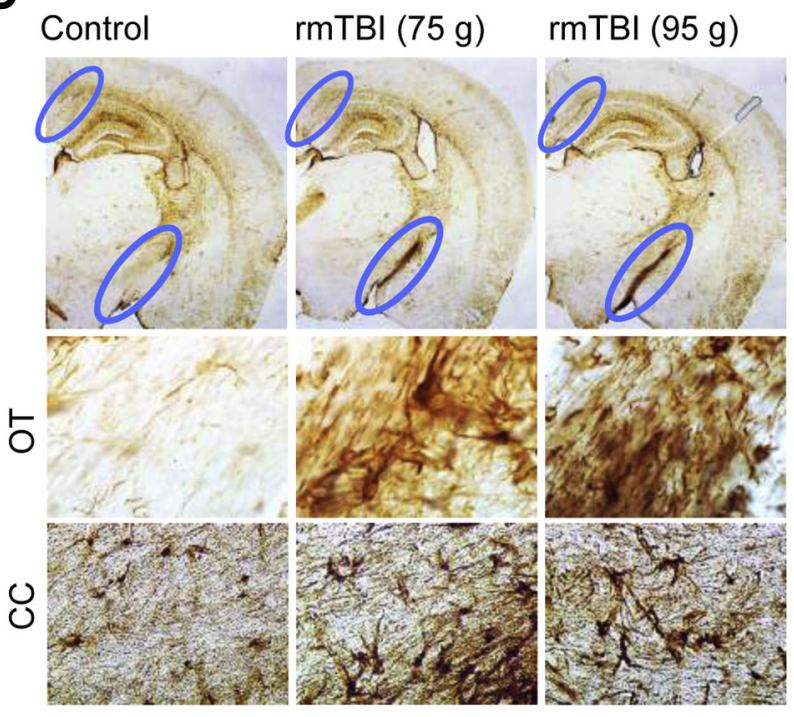

B

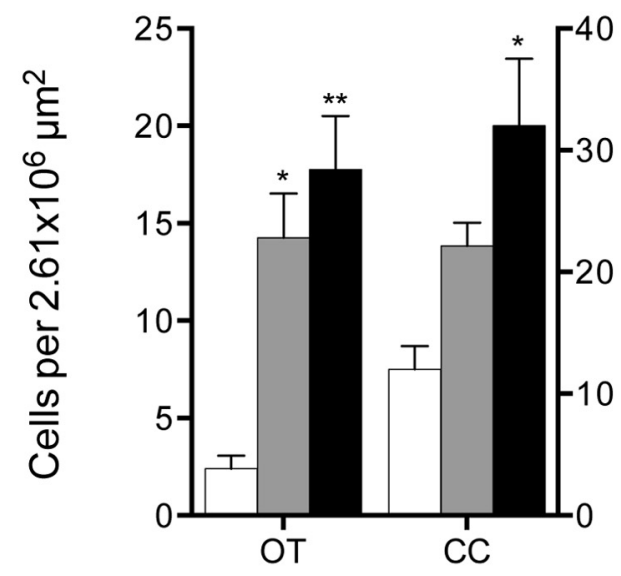

D
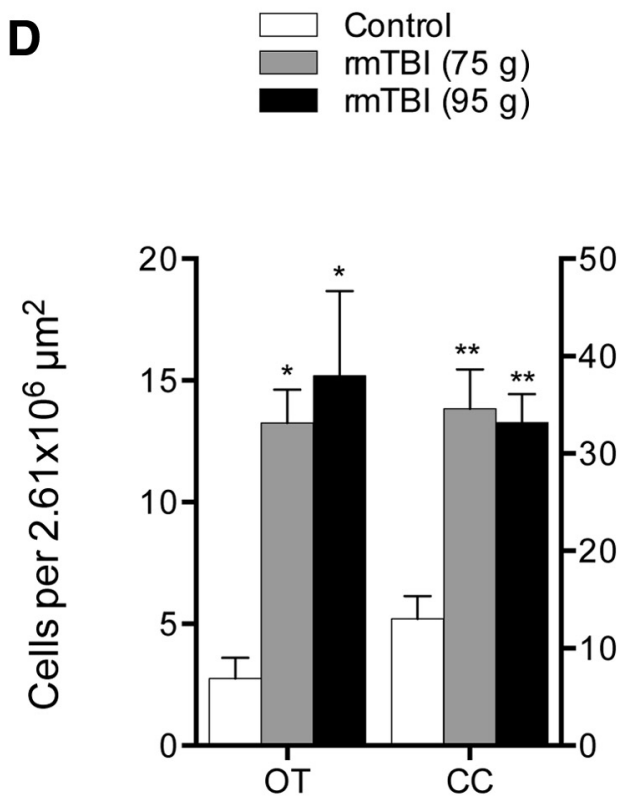

Figure 5 Repetitive mild traumatic brain injury (rmTBI) results in chronic neuroinflammation evidenced by microgliosis and astrogliosis. A: Representative photomicrographs of control, rmTBI $(75 \mathrm{~g})$, and rmTBI $(95 \mathrm{~g})$ brain sections stained using anti-Iba1. The optic tract (OT) and corpus callosum (CC) are indicated by blue ovals. B: Quantification of Iba1-labeled microglia in the OT and CC. Animals subjected to rmTBI have significantly more Iba1 labeling of activated microglia in the OT and CC compared with controls. C: Representative photomicrographs of control, rmTBI (75 g), and rmTBI (95 g) brain sections stained using anti-glial fibrillary acidic protein (GFAP). The OT and CC are indicated by blue ovals. D: Quantification of GFAP-labeled astrocytes in the 0T and CC. Animals subjected to rmTBI have significantly more GFAP in the OT and CC compared with controls. Data are expressed as means \pm SEM. $n=5$ (controls); $n=5$ (rmTBI $75 \mathrm{~g}$ ); $n=6$ (rmTBI $95 \mathrm{~g}$ ). Original magnification: $\times 2$ (A and C, top row); $\times 100$ (A and C, middle row and bottom row). ${ }^{*}<0.05$, $* * P<0.01$.

are shown in Figure 5, C and D. Control, rmTBI (75 g), and rmTBI $(95 \mathrm{~g})$ photomicrographs $(\times 2$ magnification $)$ are shown, and the OT and CC are shown at $\times 100$ magnification in Figure 5C. The main effect of treatment on GFAP expression in the OT and CC was significant as shown in Figure 5D (one-way analysis of variance; $F_{2,10}=6.978$, $P=0.0127$, and $F_{2,13}=13.97, P=0.0006$, respectively). Both rmTBI groups had significantly more GFAP in the OT
(Tukey's HSD, $P<0.05$ ) and CC (Tukey's HSD, $P<0.01$ ) compared with controls.

\section{rmTBI Results in CTE-Like Neuropathologic Conditions}

Athletes and military personnel exposed to repeated head impacts can develop CTE, ${ }^{7,34,42,43}$ so we tested mice for evidence of head impact-induced changes in $p-\tau$ and 
TDP-43, two validated markers of CTE. ${ }^{14,29,33,42}$ We found that rmTBI increased the expression of $\mathrm{p}-\tau$ in the OT and CC as shown in Figure 6, A and B. Control, rmTBI (75 g), and rmTBI $(95 \mathrm{~g})$ photomicrographs $(\times 2$ magnification $)$ are shown, and the OT and CC are shown at $\times 100$ magnification in Figure 6A. The main effect of treatment on the number of p- $\tau$-labeled cells in the OT (one-way analysis of variance; $F_{2,13}=8.474, P=0.0044$ ) and CC (one-way analysis of variance; $F_{2,14}=4296, P=0.0351$ ) was significant and is presented in Figure 6B. Compared with controls, mice in both rmTBI groups had greater amounts of $\mathrm{p}-\tau$ in the OT (Tukey's HSD, $P<0.01$ and $P<0.05$, respectively), whereas only the rmTBI (95 g) group had significantly elevated $\mathrm{p}-\tau$ in the CC compared with controls (Tukey's HSD, $P<0.05)$. The effects of rmTBI on TDP-43 are shown in Figure 6, C and D. Control, rmTBI (75 g), and rmTBI
A

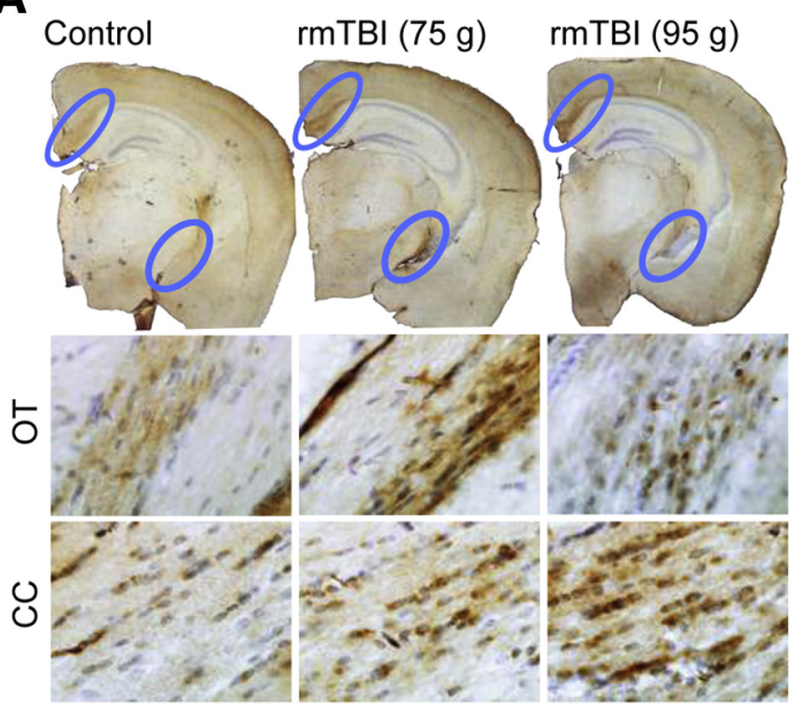

C

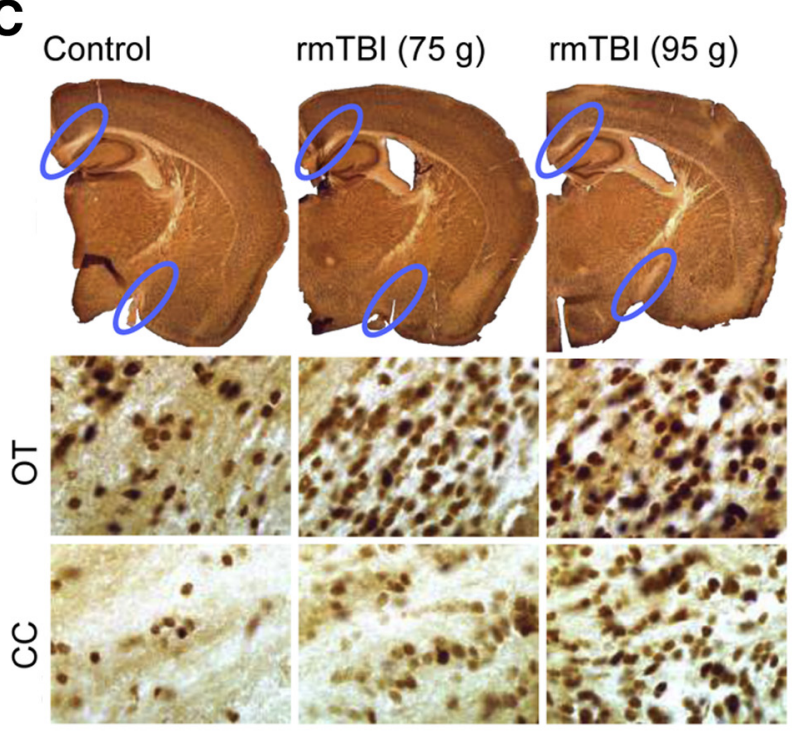

B

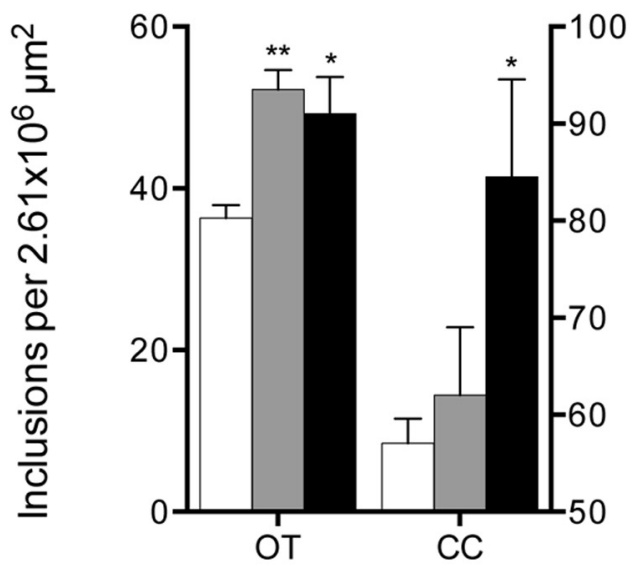

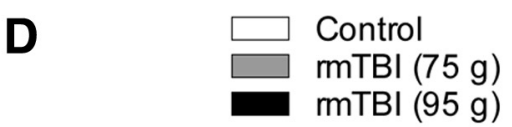

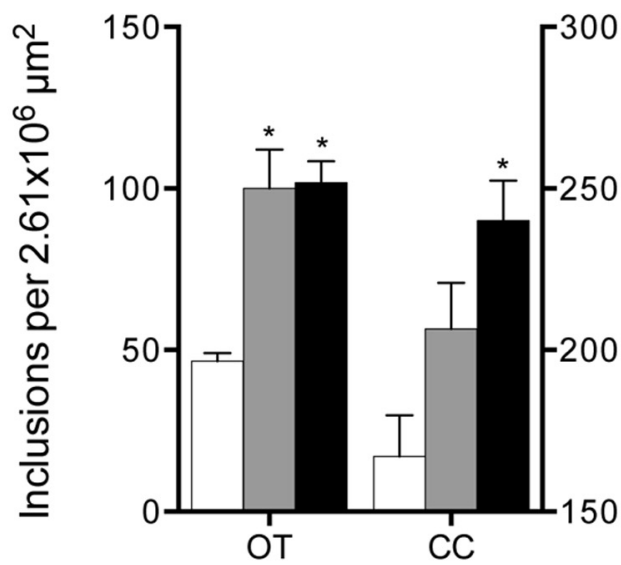

Figure 6 Repetitive mild traumatic brain injury (rmTBI) results in chronic traumatic encephalopathy-like neuropathology. A: Representative photomicrographs of control, rmTBI $(75 \mathrm{~g})$, and rmTBI $(95 \mathrm{~g})$ brain sections stained using anti-hyperphosphorylated tau (p-tau). The optic tract (0T) and corpus callosum (CC) are indicated by blue ovals. B: Quantification of p-tau in the OT and CC. Compared with controls, animals subjected to rmTBI have significantly more p-tau throughout the OT and CC. C: Representative photomicrographs of control, rmTBI (75 g), and rmTBI (95 g) brain sections stained using anti-TDP43. The $0 T$ and CC are indicated by blue ovals. D: Quantification of TDP-43 in the OT and CC. Compared with controls, animals subjected to rmTBI have significantly more TDP-43 throughout the OT and CC. Data are expressed as means \pm SEM. $n=6$ controls (B, OT and CC); $n=5$ (B, rmTBI $75 \mathrm{~g}$ and rmTBI $95 \mathrm{~g}$ for $0 \mathrm{~T}$ ); $n=6$ (B, rmTBI $75 \mathrm{~g}$ for $\mathrm{CC}) ; n=5$ (B, rmTBI $95 \mathrm{~g}$ for CC; $n=2$ controls (D, 0T); $n=2$ (D, rmTBI $75 \mathrm{~g}$ for 0T); $n=4$ (D, rmTBI $95 \mathrm{~g}$ for 0T); $n=3$ controls (D, CC); $n=5$ (D, rmTBI $75 \mathrm{~g}$ for $\mathrm{CC}) ; n=6$ (D, rmTBI $95 \mathrm{~g}$ for $\mathrm{CC})$. Original magnification: $\times 2$ (A and $\mathbf{C}$, top row); $\times 100(\mathbf{A}$ and $\mathbf{C}$, middle row and bottom row). ${ }^{*} P<0.05,{ }^{* *} P<0.01$. 
A
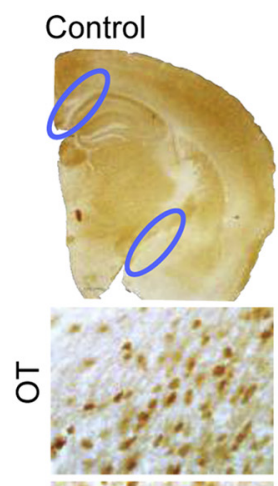

O

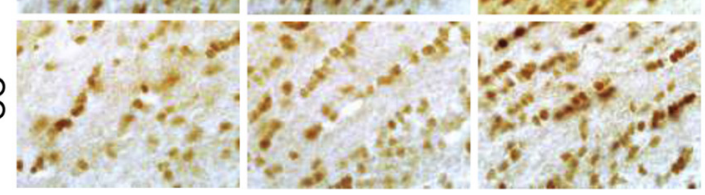

C

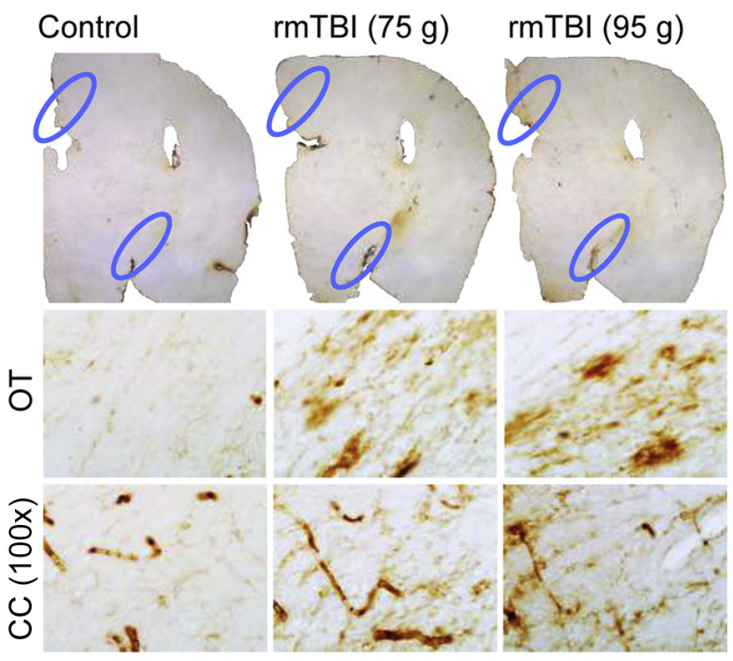

E

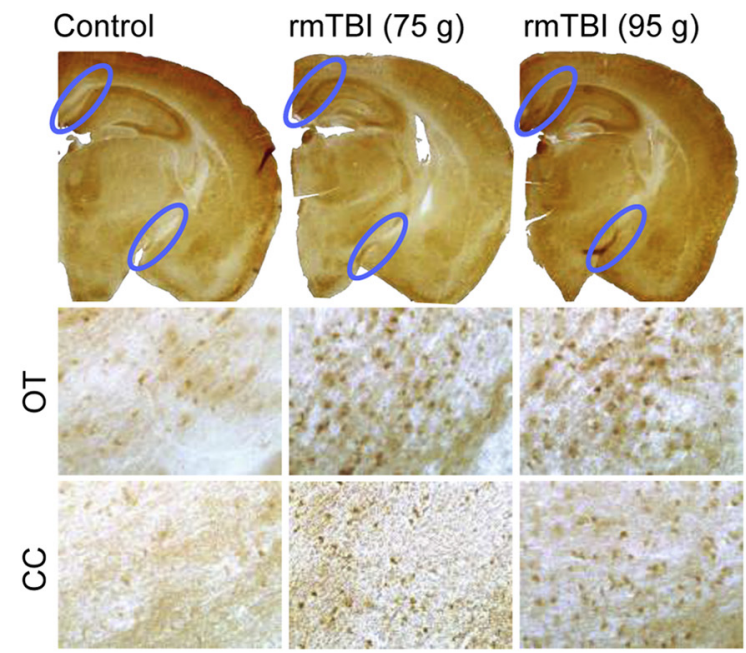

B
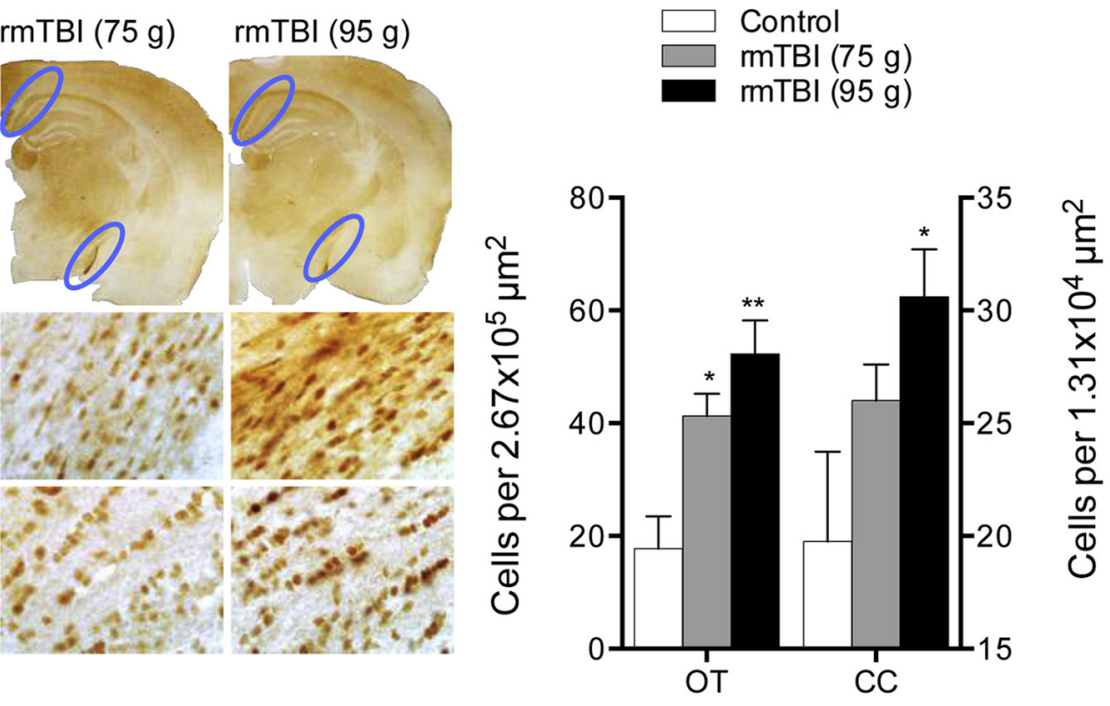

D

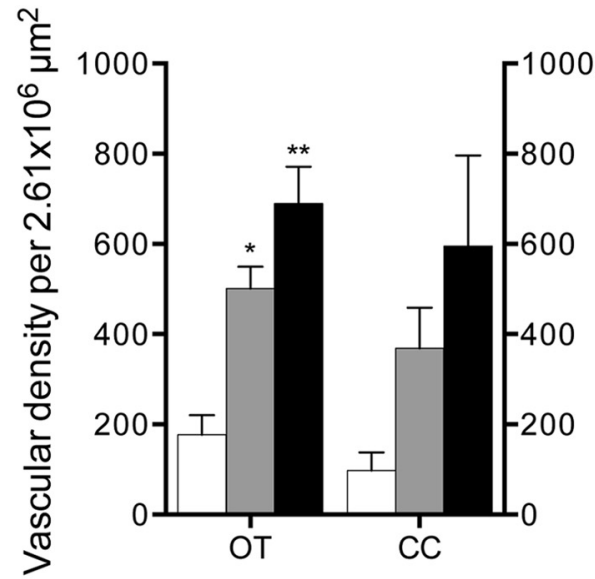

$\mathbf{F}$

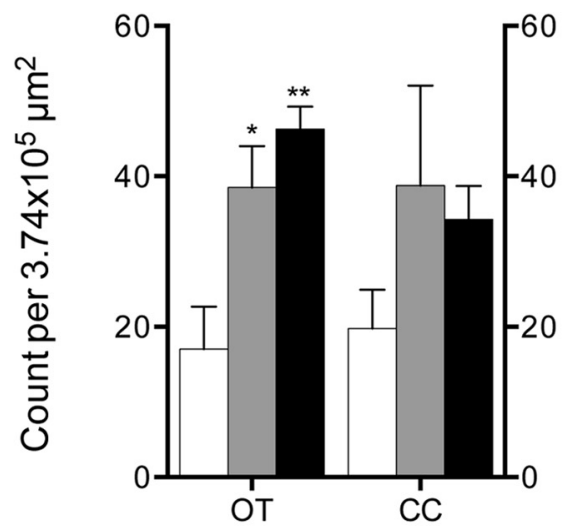


(95 g) photomicrographs $(\times 2$ magnification $)$ are shown, and the OT and CC are shown at $\times 100$ magnification in Figure $6 \mathrm{C}$. The main effect of treatment on TDP-43 expression in the OT (one-way analysis of variance; $F_{2,5}=13.40$, $P=0.0098$ ) and CC (one-way analysis of variance; $F_{2,11}=6.246, P=0.0154$ ) was significant. Compared with controls, significantly more TDP-43-labeled cells were found in the OT of both rmTBI groups (Tukey's HSD, $P<0.05$ for both), whereas TDP-43 was increased in the CC only in the rmTBI (95 g) group (Tukey's HSD, $P<0.05$ ). These results are shown in Figure 6D and indicate that the pattern of change in p- $\tau$ and TDP-43 is similar in the OT and $\mathrm{CC}$, but these white matter tracts are differentially responsive to the development of CTE-like pathologic conditions.

\section{rmTBI Results in AD-Like Neuropathologic Conditions}

Emerging research is indicating that the neuropathologic signs of CTE can include Alzheimer disease (AD)-like alterations. ${ }^{12,44-47}$ Therefore, to extend the validation of our rmTBI model in this regard, we assessed the effects of repeated head impacts on the expression of several proteins now linked to AD neuropathologic signs. The effects of rmTBI on A $\beta$ ( 1 to 42$)$ are shown in Figure 7 , A and B. Control, rmTBI (75 g), and rmTBI (95 g) photomicrographs $(\times 2$ magnification) are shown, and the OT and CC are shown at $\times 100$ magnification in Figure $7 \mathrm{~A}$. The main effect of treatment on $\mathrm{A} \beta$ ( 1 to 42 ) expression in the OT (one-way analysis of variance; $F_{2,7}=11.02, P=0.0069$ ) and $C C$ (oneway analysis of variance; $F_{2,11}=4.337, P=0.0409$ ) was significant. The levels of A $\beta$ ( 1 to 42 ) in OT were significantly increased in both rmTBI groups (Tukey's HSD, $P<0.05$ and $P<0.01$, respectively), whereas only the rmTBI (95 g) group had significant increases in A $\beta$ ( 1 to 42 ) in the CC (Tukey's HSD, $P<0.05)$ as shown in Figure 7B. The rmTBI groups had increased vascular $\beta$-amyloid staining in the CC and OT, and the results are shown in Figure 7, C and D. Control, rmTBI $(75 \mathrm{~g})$, and rmTBI (95 g) photomicrographs $(\times 2$ magnification) are shown, and the OT and CC are shown at $\times 100$ magnification in Figure $7 \mathrm{C}$. The main effect of treatment on $\beta$-amyloid accumulation in the OT was found to be significant and is shown in Figure 7D (one-way analysis of variance; $\left.F_{2,11}=11.33, P=0.0021\right)$. Mice in both $\mathrm{rmTBI}$ groups had significantly more vascular $\beta$-amyloid in the OT than controls (Tukey's HSD, $P<0.05$ and $P<0.01$, respectively). Although both rmTBI groups had elevations in $\beta$-amyloid in the $C C$, neither differed significantly from controls. The rmTBI also affected $\beta$-App expression, and the results are shown in Figure 7, E and F. Control, rmTBI (75 g), and rmTBI $(95 \mathrm{~g})$ photomicrographs $(\times 2$ magnification) are shown, and the OT and CC are shown at $\times 100$ magnification in Figure 7E. A significant main effect of treatment on $\beta$-App expression throughout the OT was found and is shown in Figure $7 \mathrm{~F}$ (one-way analysis of variance; $F_{2,11}=10.55$, $P=0.0028)$. Animals subjected to rmTBI had more $\beta$-App in the OT than controls (Tukey's HSD, $P<0.05$ ). Although the difference was not significant compared with controls $(P=0.3217)$, rmTBI also increased levels of $\beta$-App throughout the CC. These results confirm that exposure of mice to rmTBI leads to chronic AD-like neuropathologic findings throughout the OT and $\mathrm{CC}$ in addition to causing increases in reactive gliosis and markers of CTE.

\section{rmTBI Causes White Matter Thinning and Reductions in Myelin}

The significant alterations in white matter tracts seen after rmTBI led us to test if these pathological changes could be linked to structural changes in the OT and CC. This is important because individuals exposed to TBI can develop white matter losses. ${ }^{14,48-51}$ We used Luxol fast blue staining to assess gross white matter status and the effect of rmTBI on thickness of the CC is shown in Figure 8, A and $\mathrm{B}$. The width of the $\mathrm{CC}$ was measured at the two locations indicated by red arrows as shown in Figure 8A. A two-way analysis of variance revealed significant main effects of location $(F(1,20)=63.99, P<0.0001)$ and treatment $(F(2,20)=30.62, P=0.0008)$ on $C C$ width. The $C C$ was significantly thinned in both rmTBI groups compared to controls (Tukey's HSD, $P<0.01$ for both) as shown in Figure 8B. The external capsule and cingulum are indicated by red arrows and example traces of these regions are shown in Figure 8C. A significant main effect of treatment was found on the size (area) of the external capsule and cingulum (one-way analysis of variance; $F(2,13)=6.663$, $P=0.0102$ ) which were significantly smaller in animals

Figure 7 Repetitive mild traumatic brain injury (rmTBI) results in Alzheimer disease-like neuropathologic findings. A: representative photomicrographs of control, rmTBI (75 g), and rmTBI (95 g) brain sections stained using anti-A $(1$ to 42$)$. The optic tract (OT) and corpus callosum (CC) are indicated by blue ovals. B: Quantification of $A \beta$ ( 1 to 42$)$ in the $0 T$ and CC. Animals subjected to rmTBI have significantly more A $\beta$ ( 1 to 42$)$ throughout the $0 T$ and $C C$ compared with controls. C: Representative photomicrographs of control, rmTBI $(75 \mathrm{~g})$, and rmTBI $(95 \mathrm{~g})$ brain sections stained using anti- $\beta$-amyloid. The 0T and CC are indicated by blue ovals. D: Quantification of $\beta$-amyloid in the OT and CC. Animals subjected to rmTBI have significantly more vascular $\beta$-amyloid throughout the OT compared with controls. Although the difference was not significant $(P=0.1323)$, animals subjected to rmTBI had greater accumulations of vascular $\beta$-amyloid throughout the CC. E: Representative photomicrographs of control, rmTBI $(75 \mathrm{~g})$, and rmTBI $(95 \mathrm{~g})$ brain sections stained using anti- $\beta$-amyloid precursor protein ( $\beta$-App). The OT and CC are indicated by blue ovals. F: Quantification of $\beta$-App in the OT and CC. Animals subjected to rmTBI have significantly more $\beta$-App throughout the OT. Although the difference was not significant compared with controls $(P=0.3217)$, rmTBI increased levels of $\beta$-App throughout the CC. Data are expressed as means \pm SEM. $n=3$ controls (A and $\mathbf{C}) ; n=5(\mathbf{A}, \mathrm{rmTBI} 75 \mathrm{~g}) ; n=6(\mathbf{A}$ and $\mathbf{C}, \mathrm{rmTBI} 95 \mathrm{~g}) ; n=4$ controls $(\mathbf{B}, 0 \mathrm{0T}) ; n=3$ (B, rmTBI $75 \mathrm{~g}$ for 0T); $n=3$ (B, rmTBI $95 \mathrm{~g}$ for 0T); $n=4$ controls (B, CC); $n=5$ (B, rmTBI $75 \mathrm{~g}$ for CC); $n=5$ (B, rmTBI $95 \mathrm{~g}$ for CC); $n=5$ (C, rmTBI $75 \mathrm{~g}$ ); $n=6(\mathbf{C}, \mathrm{rmTBI} 95 \mathrm{~g}) ; n=3$ controls $(\mathrm{F}, 0 \mathrm{TT}) ; n=4(\mathbf{F}, \mathrm{rmTBI} 75 \mathrm{~g}$ for 0T); $n=7$ (F, rmTBI $95 \mathrm{~g}$ for 0T); $n=4$ controls $(\mathbf{F}, \mathrm{CC}) ; n=5(\mathbf{F}, \mathrm{rmTBI} 75 \mathrm{~g}$ for CC); $n=8(\mathbf{F}$, rmTBI $95 \mathrm{~g}$ for $\mathrm{CC})$. Original magnification: $\times 2\left(\mathbf{A}, \mathbf{C}\right.$, and $\mathbf{E}$, top row); $\times 100\left(\mathbf{A}, \mathbf{C}\right.$, and $\mathbf{E}$, middle row and bottom row). ${ }^{*}<0.05, * * P<0.01$. 
A

$$
\text { Control }
$$

rmTBI (75 g)

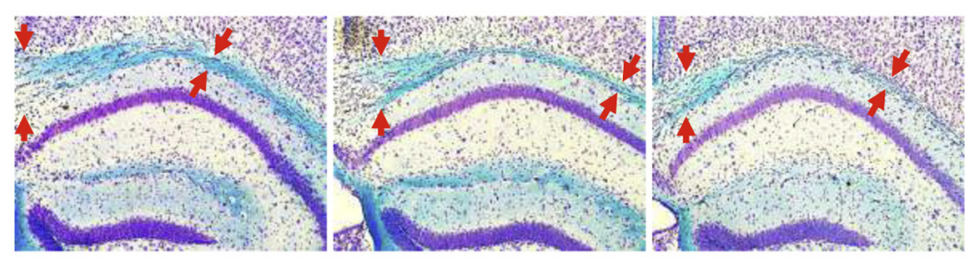

C
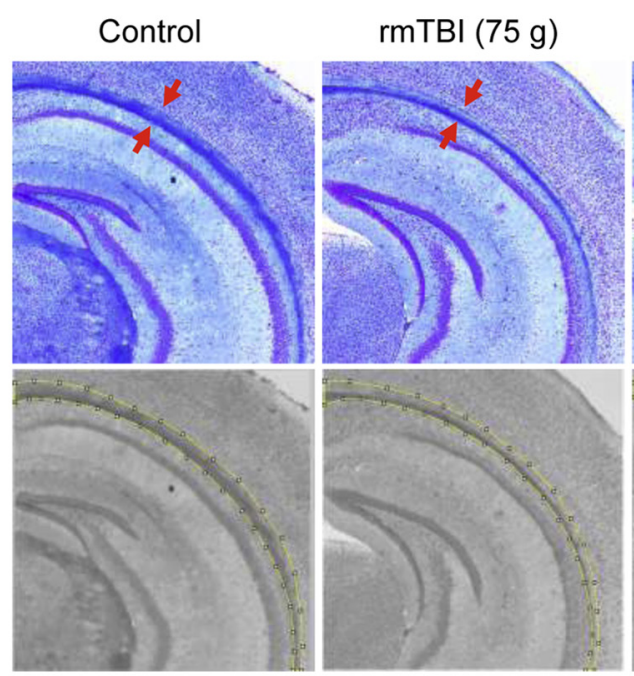

E
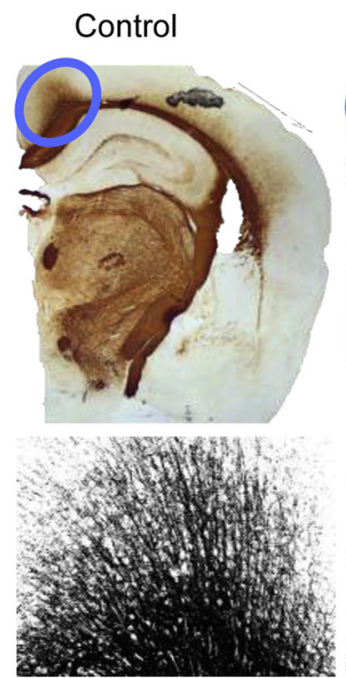

rmTBI $(75 \mathrm{~g})$
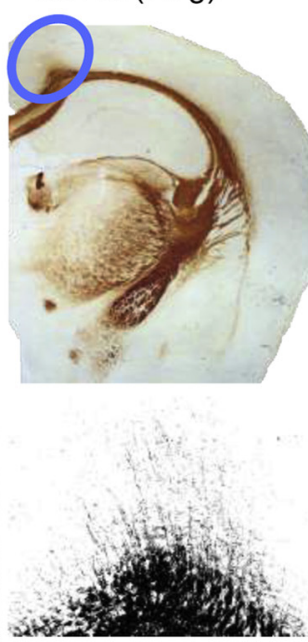

\section{rmTBI (95 g)}

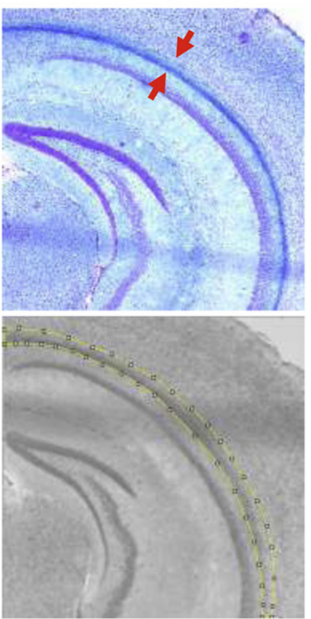

rmTBI (95 g)
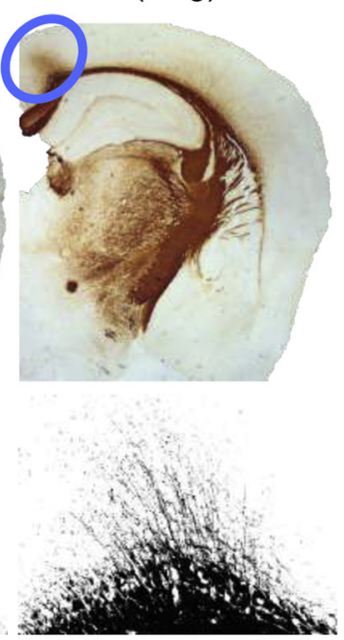

B

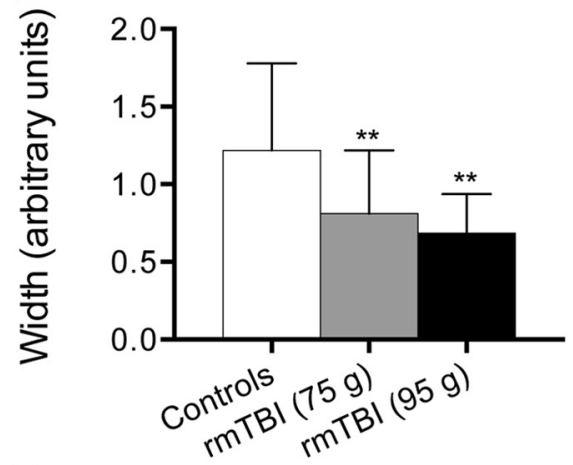

D

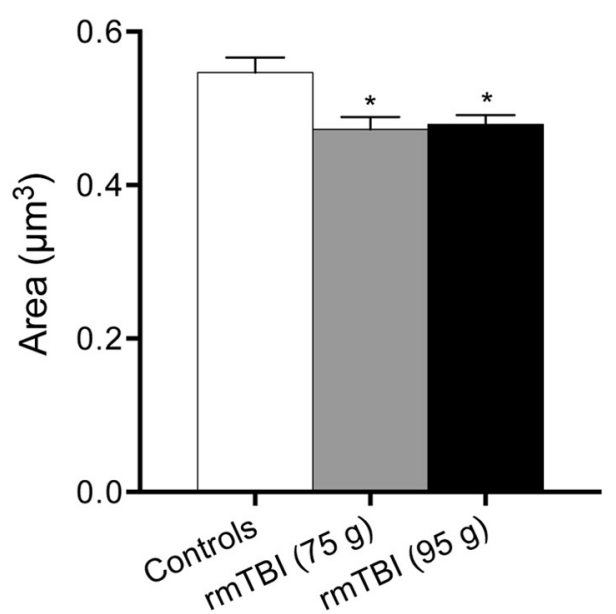

F

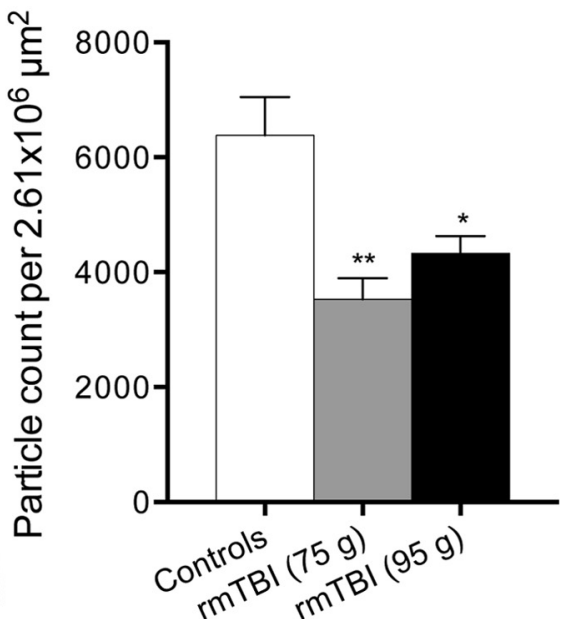

Figure 8 Repetitive mild traumatic brain injury (rmTBI) results in white matter thinning and myelin loss. A: Representative photomicrographs of control, rmTBI (75 g), and rmTBI (95 g) brain sections stained Luxol fast blue (Nissl counterstain). Arrows indicate measurement locations of the CC. B: Quantification of CC width. rmTBI results in thinning of the CC. C: Representative photomicrographs of control, rmTBI (75 g), and rmTBI (95 g) brain sections stained Luxol fast blue (Nissl counterstain) and traced images used for analysis. Arrows indicate the region of interest. D: Quantification of the area of the external capsule and cingulum. rmTBI results in thinning of the external capsule and cingulum. E: Representative photomicrographs of control, rmTBI (75 g), and rmTBI (95 g) brain sections stained using anti-myelin basic protein (MBP). The regions of interest containing myelinated fibers of the centrum semiovale are indicated by blue ovals. F: Quantification of MBP-labeled fibers. Animals subjected to rmTBI had decreased MBP in this region compared with controls. Data are expressed as means \pm SEM. $n=5$ control s (A and C); $n=5$ (A, rmTBI $75 \mathrm{~g}) ; n=3(\mathbf{A}$, rmTBI $95 \mathrm{~g}) ; n=5$ (C, rmTBI $75 \mathrm{~g}) ; n=6(\mathbf{C}$, rmTBI $95 \mathrm{~g}) ; n=3$ controls $(\mathbf{E})$; $n=5(\mathbf{E}$, rmTBI $75 \mathrm{~g}) ; n=5(\mathbf{E}$, rmTBI $95 \mathrm{~g})$. Original magnification: $\times 4(\mathbf{A}$ and $\mathbf{C}) ; \times 2(\mathbf{E}$, top row $) ; \times 20(\mathbf{E}$, bottom row $) .{ }^{*} P<0.05,{ }^{*} P<0.01$. 
subjected to rmTBI (Tukey's HSD, $P<0.05$ ) and the results are shown in Figure 8D. In light of the finding of white matter thinning, we next investigated if rmTBI had a demyelinating effect by measuring the effects of rmTBI on MBP. The results are included in Figure 8, E and F. Control, rmTBI (75 g) and rmTBI (95 g) photomicrographs $(2 \times)$ and monochrome photomicrographs $(20 \times)$ containing fibers of the centrum semiovale used for our analysis are shown in Figure 8E. The main effect of treatment on levels of MBP throughout cerebral white matter was significant (one-way analysis of variance; $F(2,10)=10.96, P=0.0030)$. Mice in both rmTBI groups showed significant reductions in the levels of MBP compared to controls as shown in Figure 8F (Tukey's HSD, $P<0.01$ for the rmTBI (75 g) group and $P<0.05$ for the rmTBI (95 g) group). These results suggest the possibility that the combined influences of reactive gliosis and increases in CTE- and AD-like neuropathologies in white matter can lead to thinning and reductions in myelin and could be indicative of axonal damage and loss.

\section{rmTBI Results in Diffuse Axonal Injury and Increased Oligodendrocyte Lineage Cells}

rmTBI resulted in diffuse axonal injury (DAI), and the results are shown in Figure 9. Control, rmTBI (75 g), and rmTBI $(95 \mathrm{~g})$ photomicrographs $(\times 2$ magnification $)$ are shown, and the OT and CC are shown at $\times 100$ magnification in Figure 9A. We performed $\chi^{2}$ tests of independence to examine the association between rmTBI and axonal damage (indicated by silver staining). There was a significant relationship between these variables. Although a larger percentage of rmTBI (75 g) animals had silver staining throughout the OT, the difference was not significant compared with controls. The rmTBI $(95 \mathrm{~g})$ group had increased silver uptake in the OT $\left(n=10, \chi_{1}^{2}=6.429\right.$, $P=0.0112)$ compared with controls, and the results are shown in Figure 9B. Compared with controls, both rmTBI groups had increased silver uptake throughout the CC [rmTBI (75 g): $n=12, \chi_{1}^{2}=4.286, P=0.0384$; rmTBI $\left.(95 \mathrm{~g}): n=11, \chi_{1}^{2}=7.639, P=0.0057\right)$ as shown in Figure 9B. Control, rmTBI (75 g), and rmTBI (95 g) photomicrographs ( $\times 2$ magnification) are shown, and the fimbria is shown at $\times 100$ magnification in Figure $9 \mathrm{C}$. The rmTBI $(95 \mathrm{~g})$ group had significantly greater silver uptake in the fimbria $\left(n=12, \chi_{1}^{2}=6.122, P=0.0133\right)$ compared with controls (Figure 9D). rmTBI caused an increase in olig2labeled oligodendrocyte lineage cells, and the results are shown in Figure 9, E and F. Control, rmTBI (75 g), and rmTBI $(95 \mathrm{~g})$ photomicrographs $(\times 2$ magnification $)$ are shown, and the OT and CC are shown at $\times 100$ magnification in Figure 9E. Although the difference was not significant, animals subjected to rmTBI had an increase in olig2-labeled oligodendroglia throughout the OT compared with controls. A significant main effect of treatment on olig2 levels throughout the CC was found and is shown in Figure 9F (one-way analysis of variance; $F_{2,9}=5.884, P=0.0232$ ).
Animals subjected to rmTBI had more olig2-labeled oligodendroglia in the CC than controls (Tukey's HSD, $P<0.05$ ).

\section{Discussion}

One indicator of the severity of a head impact is the occurrence of a concussion and particularly LOC. ${ }^{52}$ There is considerable debate in the clinical literature on the question of whether concussion and/or LOC are signs of impending neuronal injury. Concussion assessment, in patients and athletes, is variable and only moderately reliable. ${ }^{53-56}$ Players can sandbag performance on sideline tests, ${ }^{57,58}$ and many underreport concussion symptoms. ${ }^{59}$ What is more, many athletes receive numerous subconcussive blows to the head that exceed the forces known to cause concussion in other athletes, ${ }^{60}$ giving the impression that subconcussive impacts are not injurious.

The recovery of consciousness is used widely in the preclinical TBI literature as a corollary of the loss or gain of consciousness in humans exposed to head impact. In our experiment, latency to recover the righting reflex exceeded 15 minutes, only once indicating that our impacts induce a mild injury overall. ${ }^{61,62}$ One interesting finding was the gradual decrease to control levels in the time required to recover consciousness after subsequent impacts, despite the fact that the force of all impacts remained constant. This response cannot be explained as a tolerance to anesthesia because mice anesthetized to the same level as rmTBI groups but not subjected to head impact did not have a time-dependent reduction in the recovery of consciousness. This response may represent an adaptation within the central nervous system to repeated head impacts that might reflect an increase in the threshold that determines recovery of consciousness. On any given day after head-struck mice had returned to control levels for recovery of consciousness, it would appear that they had not been subjected to impact. These data could falsely signal a lack of injury and, in actuality, mask developing neuropathologic conditions. Further research investigating the synergistic or antagonistic effects of repeated exposure to anesthetics on recovery of consciousness after rmTBI is needed.

In addition to LOC, humans may have an unsteady posture or exhibit balance difficulties shortly after mild brain injury. ${ }^{16,50,63,64} \mathrm{We}$ observed significant impairments in Rotarod performance at the late test point. This may be because our injuries are quite mild and therefore insufficient to elicit immediate performance deficits. Delayed-onset sensorimotor impairment is a known correlate of CTE, and the performance deficits we observed at the later time point are consistent with this outcome. ${ }^{29}$ This finding highlights the possibility that the cumulative effect of repeated head impacts can manifest later in life despite the absence of immediate deficits and has been observed in other mouse models of rmTBI. ${ }^{28}$ Muscular weakness is also often observed in humans after mTBI, and studies have found that neuropsychomotor deficits, such as reduced grip 
A

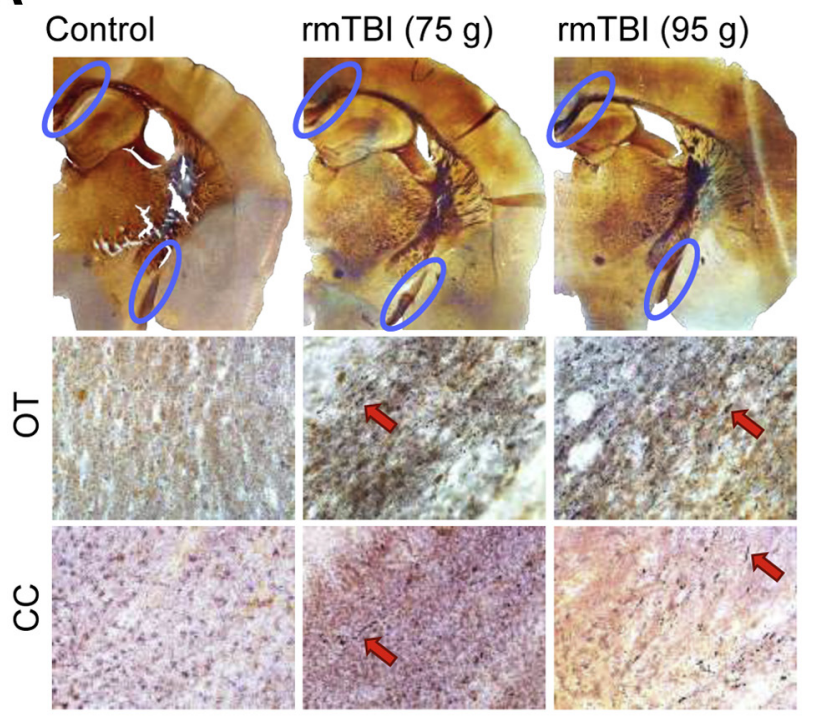

C

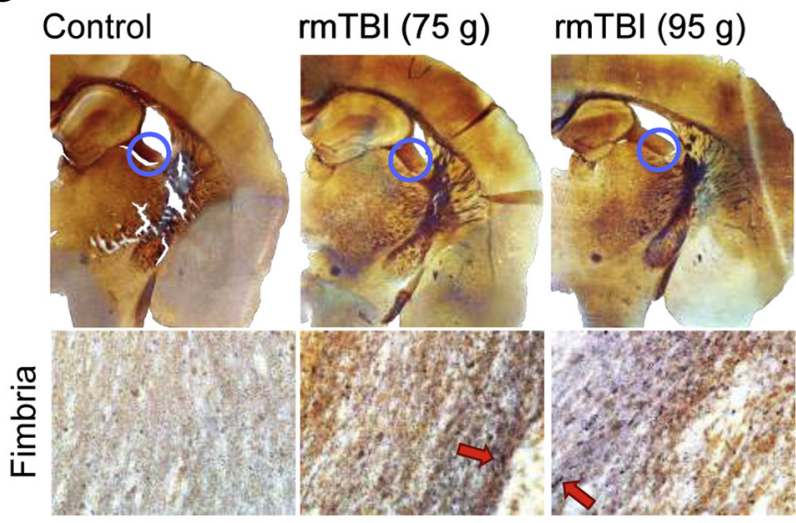

E Control

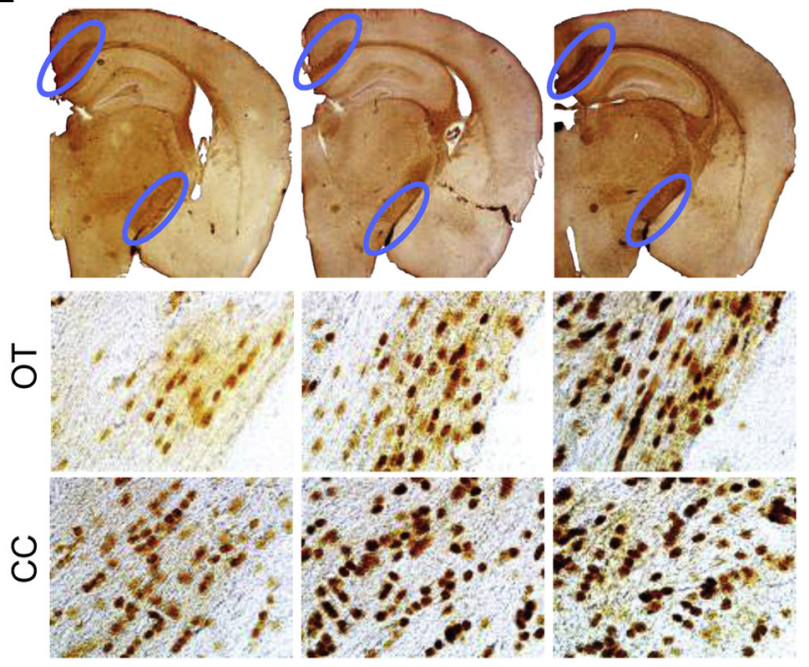

B

rmTBI (75 g)

mTBI $(95 \mathrm{~g})$

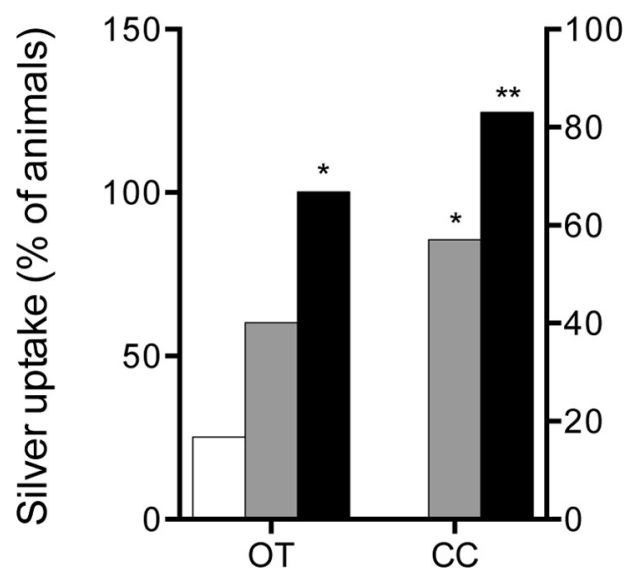

D

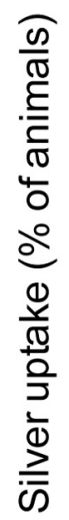

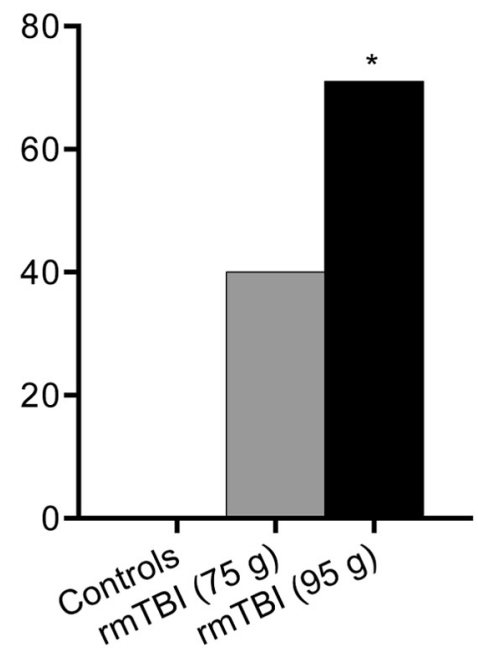

$\mathbf{F}$

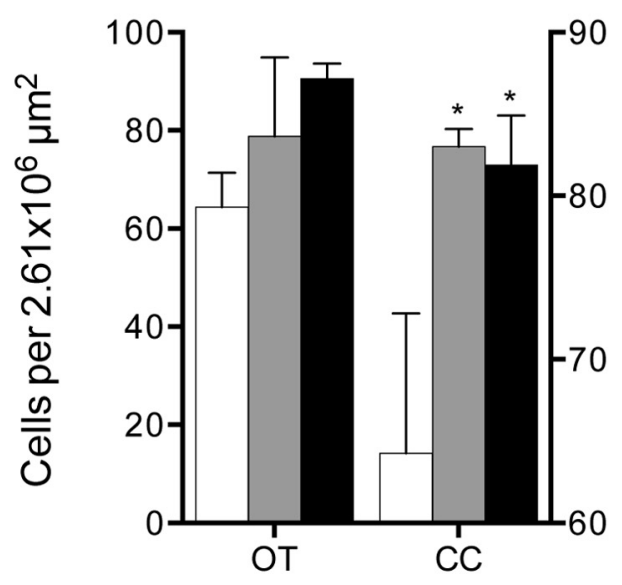


strength, do not persist after injury. ${ }^{65}$ In line with these findings, we observed an acute deficit in strength in the rmTBI (95 g) group that had resolved by the late test point.

From a psychiatric standpoint, studies in humans have found an association between recurrent concussion and diagnosis of lifetime depression, suggesting that the prevalence of depression increases with extended concussion history. ${ }^{4,66,67}$ Patients with depression often exhibit poor personal hygiene. Similarly, an animal's coat status declines with increasing depression-like behavior. ${ }^{36-38} \mathrm{We}$ observed a significant increase in depression-like behavior at both the immediate and late time points in the rmTBI (95 g) group.

Another outcome associated with TBI in humans and animal models is persistent cognitive dysfunction. ${ }^{68} \mathrm{We}$ were able to corroborate this finding using the Barnes maze. The rmTBI groups exhibited significant cognitive impairments evidenced by impaired acquisition during the training phase and poor spatial memory recall during the probe test. Similarly, an association between recurrent concussion and clinically and self-reported memory impairments has been found in retired American football players wherein those reporting $\geq 3$ concussions were five times more likely to be diagnosed as having mild cognitive impairment than those with no history of concussion. ${ }^{12}$ Similar results have been found in studies of high school and collegiate level athletes; those sustaining multiple concussions were 7.7 times more likely to exhibit significant memory impairments than athletes concussed only once. ${ }^{11}$

In humans, persistent microglial activation is involved in the neurodegeneration associated with DAI. ${ }^{69}$ We observed extreme astrogliosis and microgliosis in regions where DAI was observed, including the $\mathrm{CC}$ and OT. In addition to reactive gliosis, we observed increases in p- $\tau$ and TDP-43 throughout the CC and OT after rmTBI. Similar findings have been found in humans with other neurodegenerative diseases independent of CTE. ${ }^{70}$ We also observed significant increases in $\beta$-App, $A \beta$ ( 1 to 42 ), and vascular accumulations of $\beta$-amyloid throughout the OT and CC. A known consequence of the impaired axonal transport that results from DAI is the rapid and considerable accumulation of APP in the damaged axons, ${ }^{71,72}$ and axonal degeneration and intra-axonal $\beta$-amyloid accumulation have been identified as progressive long-term effects of TBI that persist for years in humans after injury. ${ }^{45}$ Studies using animals have found evidence of axonal damage ${ }^{73}$ and thinning of the external capsule after a single $\mathrm{TBI},{ }^{74}$ and studies of mild TBI in humans report white matter lesions in the CC, internal capsule, and centrum semiovale. ${ }^{75}$ In line with these findings, we observed significant thinning of the CC, cingulum, and external capsule after rmTBI. We also observed a reduction in MBP-labeled fibers of the centrum semiovale.

Our studies revealed that the OT and CC are particularly vulnerable structures, indicating that our method simulates the coup-countrecoup impact profile consistently observed in athletes. ${ }^{16,64,76,77}$ We observed a significant increase in axonal damage evidenced by argyrophilic silver staining in both rmTBI groups throughout the CC; however, only the 95-g group had significant damage throughout the OT and fimbria. All axons within a white matter tract are believed to suffer somewhat similar deformations during TBI, yet even in severe TBI, only a small fraction undergo transport interruption as identified by the accumulation of transported cargoes in swellings. ${ }^{78,79}$ This might explain why axonal damage (indicated by silver staining) was not observed in all animals receiving repeated head impacts. In humans with TBI, DAI has been found throughout the white matter and especially along midline structures, including the $\mathrm{CC}{ }^{80,81}$ Robust damage throughout the intracranial optic pathways has been found after fatal human TBI. ${ }^{82}$ Animal studies have also reported significant thinning, demyelination, and/ or DAI throughout the optic nerve and tract afte rmTBI. ${ }^{20,62}$ We also observed an increase in the number of olig2-labeled cells in the CC after rmTBI. Because there is a known correlation between oligodendrocyte lineage cell proliferation and myelin loss, the increase in olig2-labeled oligodendroglia may be a reparative response to the demyelination we observed after rmTBI. ${ }^{83,84}$

\section{Conclusions}

The data accumulated from the experiments in this study indicate that mild blows to the head of anesthetized mice result initially in an 8- to 10-fold increase in the time required for recovery of consciousness. The span of unconsciousness was dependent on the force of impact. As the number of daily head impacts increased, the time to recover

\footnotetext{
Figure 9 Repetitive mild traumatic brain injury (rmTBI) results in diffuse axonal injury and increases oligodendrocyte lineage cells. A: Representative photomicrographs of control, rmTBI $(75 \mathrm{~g})$, and rmTBI $(95 \mathrm{~g})$ brain sections stained using stained using the FD Neurosilver kit II. The optic tract (0T) and corpus callosum (CC) are indicated by blue ovals. Red arrows indicate degenerating axons. B: Quantification of percentage of animals with evidence of axonal silver uptake. Animals subjected to rmTBI had increased silver uptake in the $\mathrm{OT}$ and CC compared with controls. C: Representative photomicrographs of control, rmTBI $(75 \mathrm{~g})$, and rmTBI $(95 \mathrm{~g})$ brain sections stained using stained using the FD Neurosilver kit II. The fimbria of the hippocampus is indicated by blue circles. Red arrows indicate degenerating axons. D: Quantification of percentage of animals with evidence of axonal silver uptake. Animals subjected to rmTBI had increased silver uptake in the fimbria compared with controls. E: Representative photomicrographs of control, rmTBI (75 g), and rmTBI (95 g) brain sections stained using anti-olig2. The OT and CC are indicated by blue ovals. F: Quantification of olig2-labeled cells in the OT and CC. Animals subjected to rmTBI had significantly more olig2 throughout the $\mathrm{CC}$ compared with controls. Although the difference was not significant $(P=0.4243)$, animals subjected to rmTBI had more olig2-labeled cells throughout the 0T. Data are expressed as means \pm SEM. $n=5$ controls $(\mathbf{A}$ and $\mathbf{C}) ; n=(\mathbf{A}$ and $\mathbf{C}, 5 \mathrm{rmTBI} 75 \mathrm{~g}) ; n=6(\mathbf{A}$ and $\mathbf{C}$, rmTBI $95 \mathrm{~g}) ; n=3$ controls $(\mathbf{E}) ; n=5(\mathbf{E}$, rmTBI $75 \mathrm{~g}) ; n=4(\mathbf{E}, \mathrm{rmTBI} 95 \mathrm{~g})$. Original magnification: $\times 2(\mathbf{A}, \mathbf{C}$, and $\mathbf{E}$, top row $) ; \times 100(\mathbf{A}$ and $\mathbf{E}$, middle row and bottom row, and $\mathrm{C}$, bottom row). ${ }^{*} P<0.05,{ }^{*} P<0.01$.
} 
consciousness gradually adapted and eventually diminished to levels seen in anesthetized mice not subjected to head impacts. On the basis of recovery of consciousness after additional impacts thereafter, head-struck mice could not be differentiated from naïve mice, and their behavior indicative was not indicative of central nervous system injury in the minutes and hours after an impact. Despite the fact that head-struck mice had no more signs of concussion than controls, the sensorimotor function and behavior of these mice evolved in the ensuing weeks to include mild problems with balance and coordination, reductions in grip strength, and emergence of affective-like behavior and cognitive impairment. With the passage of additional time, the reduction in grip strength resolved while the impairments in coordination and depression-like behavior persisted. Examination of the brains of mice approximately 2 months after the last head impact revealed the development of significant neuropathologic changes, particularly in white matter tracts distant from the point of impact on the skull. The neuropathologic changes included increased reactive gliosis, CTE-like increases in $\mathrm{p}-\tau$ and TDP-43, and AD-like expression of $A \beta$ ( 1 to 42$)$ and vascular $\beta$-amyloid. In summary, the behavioral and neuropathologic outcomes caused by the administration of 30 head impacts to lightly anesthetized, completely unrestrained mice establish a paradigm that simulates the truly repetitive nature of sportsand military-related head impacts. This model will enable future study of the most pressing issues associated with repetitive head impacts, including the association between the number and frequency of head impacts to the development of CTE-like outcomes and the identification of factors that put some individuals at greater risk for the development of chronic injury. Future studies elucidating the cellular manifestations of rmTBI and its behavioral correlates will aid in the development, rapid identification, and testing of novel pharmacotherapies for rmTBI, ultimately improving the lives of those afflicted.

\section{References}

1. Langlois JA, Rutland-Brown W, Wald MM: The epidemiology and impact of traumatic brain injury: a brief overview. J Head Trauma Rehabil 2006, 21:375-378

2. Faul M, Xu L, Wald M, Coronado V, Dellinger AM: Traumatic brain injury in the United States: national estimates of prevalence and incidence, 2002-2006. Inj Prev 2010, 16:A268

3. Mooney G, Speed J: The association between mild traumatic brain injury and psychiatric conditions. Brain Inj 2001, 15:865-877

4. Holsinger T, Steffens DC, Phillips C, Helms MJ, Havlik RJ, Breitner JC, Guralnik JM, Plassman BL: Head injury in early adulthood and the lifetime risk of depression. Arch Gen Psychiatry 2002, 59:17-22

5. Guskiewicz KM, Marshall SW, Bailes J, McCrea M, Harding HP Jr, Matthews A, Mihalik JR, Cantu RC: Recurrent concussion and risk of depression in retired professional football players. Med Sci Sports Exerc 2007, 39:903-909

6. Kerr ZY, Marshall SW, Harding HP Jr, Guskiewicz KM: Nine-year risk of depression diagnosis increases with increasing self-reported concussions in retired professional football players. Am J Sports Med 2012, 40:2206-2212

7. Gavett BE, Stern RA, McKee AC: Chronic traumatic encephalopathy: a potential late effect of sport-related concussive and subconcussive head trauma. Clin Sports Med 2011, 30:179-188

8. Schatz P, Moser RS, Covassin T, Karpf R: Early indicators of enduring symptoms in high school athletes with multiple previous concussions. Neurosurgery 2011, 68:1562-1567; discussion 7

9. Broglio SP, Eckner JT, Martini D, Sosnoff JJ, Kutcher JS, Randolph C: Cumulative head impact burden in high school football. J Neurotrauma 2011, 28:2069-2078

10. Arciniegas D, Held K, Wagner P: Cognitive impairment following traumatic brain injury. Curr Treat Options Neurol 2002, 4:43-57

11. Iverson GL, Gaetz M, Lovell MR, Collins MW: Cumulative effects of concussion in amateur athletes. Brain Inj 2004, 18:433-443

12. Guskiewicz KM, Marshall SW, Bailes J, McCrea M, Cantu RC, Randolph C, Jordan BD: Association between recurrent concussion and late-life cognitive impairment in retired professional football players. Neurosurgery 2005, 57:719-726; discussion -26

13. Stern RA, Riley DO, Daneshvar DH, Nowinski CJ, Cantu RC, McKee AC: Long-term consequences of repetitive brain trauma: chronic traumatic encephalopathy. PM R 2011, 3:S460-S467

14. McKee AC, Stern RA, Nowinski CJ, Stein TD, Alvarez VE, Daneshvar DH, Lee HS, Wojtowicz SM, Hall G, Baugh CM, Riley DO, Kubilus CA, Cormier KA, Jacobs MA, Martin BR, Abraham CR, Ikezu T, Reichard RR, Wolozin BL, Budson AE, Goldstein LE, Kowall NW, Cantu RC: The spectrum of disease in chronic traumatic encephalopathy. Brain 2013, 136:43-64

15. Maxwell W, Bartlet E, Morgan H: Wallerian degeneration in the optic nerve stretch-injury model of TBI: a stereological analysis. J Neurotrauma $2015,32: 780-790$

16. Daneshvar DH, Nowinski CJ, McKee AC, Cantu RC: The epidemiology of sport-related concussion. Clin Sports Med 2011, 30:1-17, vii

17. Mouzon B, Chaytow H, Crynen G, Bachmeier C, Stewart J, Mullan M, Stewart W, Crawford F: Repetitive mild traumatic brain injury in a mouse model produces learning and memory deficits accompanied by histological changes. J Neurotrauma 2012, 29: $2761-2773$

18. Ojo JO, Bachmeier C, Mouzon BC, Tzekov R, Mullan M, Davies H, Stewart MG, Crawford F: Ultrastructural changes in the white and gray matter of mice at chronic time points after repeated concussive head injury. J Neuropathol Exp Neurol 2015, 74:1012-1035

19. Ojo JO, Mouzon B, Greenberg MB, Bachmeier C, Mullan M, Crawford F: Repetitive mild traumatic brain injury augments tau pathology and glial activation in aged hTau mice. J Neuropathol Exp Neurol 2013, 72:137-151

20. Tzekov R, Quezada A, Gautier M, Biggins D, Frances C, Mouzon B Jamison J, Mullan M, Crawford F: Repetitive mild traumatic brain injury causes optic nerve and retinal damage in a mouse model. J Neuropathol Exp Neurol 2014, 73:345-361

21. Mannix R, Berglass J, Berkner J, Moleus P, Qiu JH, Andrews N, Gunner G, Berglass L, Jantzie LL, Robinson S, Meehan WP: Chronic gliosis and behavioral deficits in mice following repetitive mild traumatic brain injury. J Neurosurgery 2014, 121:1342-1350

22. Mannix R, Meehan WP, Mandeville J, Grant PE, Gray T, Berglass J, Zhang J, Bryant J, Rezaie S, Chung JY, Peters NV, Lee C, Tien LW, Kaplan DL, Feany M, Whalen M: Clinical correlates in an experimental model of repetitive mild brain injury. Ann Neurol 2013, 74:65-75

23. Xu L, Nguyen JV, Lehar M, Menon A, Rha E, Arena J, Ryu J, Marsh-Armstrong N, Marmarou CR, Koliatsos VE: Repetitive mild traumatic brain injury with impact acceleration in the mouse: multifocal axonopathy, neuroinflammation, and neurodegeneration in the visual system. Exp Neurol 2016, 275 Pt 3:436-449

24. Xu L, Ryu J, Nguyen JV, Arena J, Rha E, Vranis P, Hitt D, MarshArmstrong N, Koliatsos VE: Evidence for accelerated tauopathy in the retina of transgenic P301S tau mice exposed to repetitive mild traumatic brain injury. Exp Neurol 2015, 273:168-176 
25. Kane MJ, Angoa-Perez M, Briggs DI, Viano DC, Kreipke CW, Kuhn DM: A mouse model of human repetitive mild traumatic brain injury. J Neurosci Methods 2012, 203:41-49

26. Petraglia AL, Plog BA, Dayawansa S, Chen M, Dashnaw ML, Czerniecka K, Walker CT, Viterise T, Hyrien O, Iliff JJ, Deane R, Nedergaard M, Huang JH: The spectrum of neurobehavioral sequelae after repetitive mild traumatic brain injury: a novel mouse model of chronic traumatic encephalopathy. J Neurotrauma 2014, 31: 1211-1224

27. Petraglia AL, Plog BA, Dayawansa S, Dashnaw ML, Czerniecka K, Walker CT, Chen M, Hyrien O, Iliff JJ, Deane R, Huang JH, Nedergaard M: The pathophysiology underlying repetitive mild traumatic brain injury in a novel mouse model of chronic traumatic encephalopathy. Surg Neurol Int 2014, 5:184

28. Winston CN, Noel A, Neustadtl A, Parsadanian M, Barton DJ, Chellappa D, Wilkins TE, Alikhani AD, Zapple DN, Villapol S, Planel E, Burns MP: Dendritic spine loss and chronic white matter inflammation in a mouse model of highly repetitive head trauma. Am J Pathol 2016, 186:552-567

29. McKee AC, Cantu RC, Nowinski CJ, Hedley-Whyte ET, Gavett BE, Budson AE, Santini VE, Lee HS, Kubilus CA, Stern RA: Chronic traumatic encephalopathy in athletes: progressive tauopathy after repetitive head injury. J Neuropathol Exp Neurol 2009, 68:709-735

30. Hall ED, Pazara KE, Linseman KL: Sex differences in postischemic neuronal necrosis in gerbils. J Cereb Blood Flow Metab 1991, 11: 292-298

31. Roof RL, Hall ED: Estrogen-related gender difference in survival rate and cortical blood flow after impact-acceleration head injury in rats. $\mathrm{J}$ Neurotrauma 2000, 17:1155-1169

32. Brann DW, Dhandapani K, Wakade C, Mahesh VB, Khan MM: Neurotrophic and neuroprotective actions of estrogen: basic mechanisms and clinical implications. Steroids 2007, 72:381-405

33. McKee AC, Gavett BE, Stern RA, Nowinski CJ, Cantu RC, Kowall NW, Perl DP, Hedley-Whyte ET, Price B, Sullivan C, Morin P, Lee HS, Kubilus CA, Daneshvar DH, Wulff M, Budson AE: TDP-43 proteinopathy and motor neuron disease in chronic traumatic encephalopathy. J Neuropathol Exp Neurol 2010, 69:918-929

34. Goldstein LE, Fisher AM, Tagge CA, Zhang XL, Velisek L, Sullivan JA, Upreti C, Kracht JM, Ericsson M, Wojnarowicz MW, Goletiani CJ, Maglakelidze GM, Casey N, Moncaster JA, Minaeva O, Moir RD, Nowinski CJ, Stern RA, Cantu RC, Geiling J, Blusztajn JK, Wolozin BL, Ikezu T, Stein TD, Budson AE, Kowall NW, Chargin D, Sharon A, Saman S, Hall GF, Moss WC, Cleveland RO, Tanzi RE, Stanton PK, McKee AC: Chronic traumatic encephalopathy in blast-exposed military veterans and a blast neurotrauma mouse model. Sci Transl Med 2012, 4:134ra60

35. Deacon RM: Measuring the strength of mice. J Vis Exp 2013, 76: e2610

36. Yalcin I, Aksu F, Belzung C: Effects of desipramine and tramadol in a chronic mild stress model in mice are altered by yohimbine but not by pindolol. Eur J Pharmacol 2005, 514:165-174

37. Yalcin I, Aksu F, Bodard S, Chalon S, Belzung C: Antidepressantlike effect of tramadol in the unpredictable chronic mild stress procedure: possible involvement of the noradrenergic system. Behav Pharmacol 2007, 18:623-631

38. Piato AL, Detanico BC, Jesus JF, Lhullier FL, Nunes DS, Elisabetsky E: Effects of Marapuama in the chronic mild stress model: further indication of antidepressant properties. J Ethnopharmacol 2008, 118:300-304

39. O'Leary TP, Brown RE: Visuo-spatial learning and memory deficits on the Barnes maze in the 16-month-old APPswe/PS1dE9 mouse model of Alzheimer's disease. Behav Brain Res 2009, 201:120-127

40. Thomas DM, Francescutti-Verbeem DM, Kuhn DM: The newly synthesized pool of dopamine determines the severity of methamphetamineinduced neurotoxicity. J Neurochem 2008, 105:605-616

41. Franklin KBJ, Paxinos G: The mouse brain in stereotaxic coordinates. ed 3. Amsterdam, Boston: Elsevier/Academic Press, 2008
42. Baugh CM, Stamm JM, Riley DO, Gavett BE, Shenton ME, Lin A, Nowinski CJ, Cantu RC, McKee AC, Stern RA: Chronic traumatic encephalopathy: neurodegeneration following repetitive concussive and subconcussive brain trauma. Brain Imaging Behav 2012, 6: 244-254

43. McKee AC, Robinson ME: Military-related traumatic brain injury and neurodegeneration. Alzheimers Dement 2014, 10:S242-S253

44. Blennow K, Hardy J, Zetterberg H: The neuropathology and neurobiology of traumatic brain injury. Neuron 2012, 76:886-899

45. Chen XH, Johnson VE, Uryu K, Trojanowski JQ, Smith DH: A lack of amyloid beta plaques despite persistent accumulation of amyloid beta in axons of long-term survivors of traumatic brain injury. Brain Pathol 2009, 19:214-223

46. Fleminger S: Long-term psychiatric disorders after traumatic brain injury. Eur J Anaesthesiol Suppl 2008, 42:123-130

47. Roberts GW, Allsop D, Bruton C: The occult aftermath of boxing. J Neurol Neurosurg Psychiatry 1990, 53:373-378

48. Armstrong RC, Mierzwa AJ, Sullivan GM, Sanchez MA: Myelin and oligodendrocyte lineage cells in white matter pathology and plasticity after traumatic brain injury. Neuropharmacology 2015, [Epub ahead of print] doi:10.1016/j.neuropharm.2015.04.029

49. Bendlin BB, Ries ML, Lazar M, Alexander AL, Dempsey RJ, Rowley HA, Sherman JE, Johnson SC: Longitudinal changes in patients with traumatic brain injury assessed with diffusion-tensor and volumetric imaging. Neuroimage 2008, 42:503-514

50. Cubon VA, Putukian M, Boyer C, Dettwiler A: A diffusion tensor imaging study on the white matter skeleton in individuals with sportsrelated concussion. J Neurotrauma 2011, 28:189-201

51. Farbota KD, Sodhi A, Bendlin BB, McLaren DG, Xu G, Rowley HA, Johnson SC: Longitudinal volumetric changes following traumatic brain injury: a tensor-based morphometry study. J Int Neuropsychol Soc 2012, 18:1006-1018

52. McCrory P, Meeuwisse WH, Echemendia RJ, Iverson GL, Dvorak J, Kutcher JS: What is the lowest threshold to make a diagnosis of concussion? Br J Sports Med 2013, 47:268-271

53. Resch J, Driscoll A, McCaffrey N, Brown C, Ferrara MS, Macciocchi S, Baumgartner T, Walpert K: ImPact test-retest reliability: reliably unreliable? J Athl Train 2013, 48:506-511

54. Schatz P, Pardini JE, Lovell MR, Collins MW, Podell K: Sensitivity and specificity of the ImPACT Test Battery for concussion in athletes. Arch Clin Neuropsychol 2006, 21:91-99

55. Reith FC, Brennan PM, Maas AI, Teasdale GM: Lack of standardization in the use of the Glasgow Coma Scale: results of international surveys. J Neurotrauma 2016, 33:89-94

56. Alsalaheen B, Stockdale K, Pechumer D, Broglio SP: Measurement error in the Immediate Postconcussion Assessment and Cognitive Testing (ImPACT): systematic review. J Head Trauma Rehabil 2016, $31: 242-251$

57. Szabo AJ, Alosco ML, Fedor A, Gunstad J: Invalid performance and the ImPACT in National Collegiate Athletic Association Division I football players. J Athl Train 2013, 48:851-855

58. Schatz P, Glatts C: "Sandbagging" baseline test performance on ImPACT, without detection, is more difficult than it appears. Arch Clin Neuropsychol 2013, 28:236-244

59. Meier TB, Brummel BJ, Singh R, Nerio CJ, Polanski DW, Bellgowan PS: The underreporting of self-reported symptoms following sports-related concussion. J Sci Med Sport 2015, 18:507-511

60. Beckwith JG, Greenwald RM, Chu JJ, Crisco JJ, Rowson S, Duma SM, Broglio SP, McAllister TW, Guskiewicz KM, Mihalik JP, Anderson S, Schnebel B, Brolinson PG, Collins MW: Head impact exposure sustained by football players on days of diagnosed concussion. Med Sci Sports Exerc 2013, 45:737-746

61. Dewitt DS, Perez-Polo R, Hulsebosch CE, Dash PK, Robertson CS: Challenges in the development of rodent models of mild traumatic brain injury. J Neurotrauma 2013, 30:688-701

62. Namjoshi DR, Cheng WH, McInnes KA, Martens KM, Carr M, Wilkinson A, Fan JJ, Robert J, Hayat A, Cripton PA, Wellington CL: 
Merging pathology with biomechanics using CHIMERA (ClosedHead Impact Model of Engineered Rotational Acceleration): a novel, surgery-free model of traumatic brain injury. Mol Neurodegener 2014, 9:688

63. Guskiewicz KM, McCrea M, Marshall SW, Cantu RC, Randolph C, Barr W, Onate JA, Kelly JP: Cumulative effects associated with recurrent concussion in collegiate football players: the NCAA Concussion Study. JAMA 2003, 290:2549-2555

64. Daneshvar DH, Baugh CM, Nowinski CJ, McKee AC, Stern RA, Cantu RC: Helmets and mouth guards: the role of personal equipment in preventing sport-related concussions. Clin Sports Med 2011, 30: $145-163, x$

65. Greiffenstein MF, Baker WJ, Gola T: Motor dysfunction profiles in traumatic brain injury and postconcussion syndrome. J Int Neuropsychol Soc 1996, 2:477-485

66. Leon-Carrion J, de Serdio-Arias ML, Cabezas FM, Roldan JMD, Dominguez-Morales R, Martin JMBY, Sanchez MAM: Neurobehavioural and cognitive profile of traumatic brain injury patients at risk for depression and suicide. Brain Inj 2001, 15:175-181

67. Teasdale TW, Engberg AW: Suicide after traumatic brain injury: a population study. J Neurol Neurosurg Psychiatry 2001, 71: 436-440

68. Bales JW, Wagner AK, Kline AE, Dixon CE: Persistent cognitive dysfunction after traumatic brain injury: a dopamine hypothesis. Neurosci Biobehav Rev 2009, 33:981-1003

69. Lucke-Wold BP, Turner RC, Logsdon AF, Bailes JE, Huber JD, Rosen CL: Linking traumatic brain injury to chronic traumatic encephalopathy: identification of potential mechanisms leading to neurofibrillary tangle development. J Neurotrauma 2014, 31: $1129-1138$

70. Walker AK, Daniels CM, Goldman JE, Trojanowski JQ, Lee VM, Messing A: Astrocytic TDP-43 pathology in Alexander disease. J Neurosci 2014, 34:6448-6458

71. Gentleman SM, Nash MJ, Sweeting CJ, Graham DI, Roberts GW: Beta-amyloid precursor protein (beta-App) as a marker for axonal injury after head-injury. Neurosci Lett 1993, 160:139-144
72. Uryu $\mathrm{K}$, Chen XH, Martinez D, Browne KD, Johnson VE, Graham DI, Lee VM, Trojanowski JQ, Smith DH: Multiple proteins implicated in neurodegenerative diseases accumulate in axons after brain trauma in humans. Exp Neurol 2007, 208:185-192

73. Spain A, Daumas S, Lifshitz J, Rhodes J, Andrews PJ, Horsburgh K, Fowler JH: Mild fluid percussion injury in mice produces evolving selective axonal pathology and cognitive deficits relevant to human brain injury. J Neurotrauma 2010, 27:1429-1438

74. Bramlett HM, Dietrich WD: Quantitative structural changes in white and gray matter 1 year following traumatic brain injury in rats. Acta Neuropathol 2002, 103:607-614

75. Inglese M, Makani S, Johnson G, Cohen BA, Silver JA, Gonen O, Grossman RI: Diffuse axonal injury in mild traumatic brain injury: a diffusion tensor imaging study. J Neurosurgery 2005, 103:298-303

76. Denny-Brown, Russell WR: Experimental cerebral concussion. The J Physiology 1940, 99:153

77. Holbourn AHS: Mechanics of head injuries. Lancet 1943, 2:438-441

78. Johnson VE, Stewart JE, Begbie FD, Trojanowski JQ, Smith DH, Stewart W: Inflammation and white matter degeneration persist for years after a single traumatic brain injury. Brain 2013, 136:28-42

79. Johnson VE, Stewart W, Smith DH: Axonal pathology in traumatic brain injury. Exp Neurol 2013, 246:35-43

80. Meythaler JM, Peduzzi JD, Eleftheriou E, Novack TA: Current concepts: diffuse axonal injury-associated traumatic brain injury. Arch Phys Med Rehabil 2001, 82:1461-1471

81. Smith DH, Meaney DF, Shull WH: Diffuse axonal injury in head trauma. J Head Trauma Rehabil 2003, 18:307-316

82. Perunovic B, Quilty RD, Athanasiou A, Love S: Damage to intracranial optic pathways in fatal closed head injury in man. J Neurol Sci 2001, 185:55-62

83. Tan AM, Zhang W, Levine JM: NG2: a component of the glial scar that inhibits axon growth. J Anat 2005, 207:717-725

84. Di Bello IC, Dawson MR, Levine JM, Reynolds R: Generation of oligodendroglial progenitors in acute inflammatory demyelinating lesions of the rat brain stem is associated with demyelination rather than inflammation. J Neurocytol 1999, 28:365-381 